NBER WORKING PAPER SERIES

\title{
BIRTH ORDER AND DELINQUENCY: EVIDENCE FROM DENMARK AND FLORIDA
}

\author{
Sanni N. Breining \\ Joseph J. Doyle, Jr. \\ David N. Figlio \\ Krzysztof Karbownik \\ Jeffrey Roth \\ Working Paper 23038 \\ http://www.nber.org/papers/w23038 \\ NATIONAL BUREAU OF ECONOMIC RESEARCH \\ 1050 Massachusetts Avenue \\ Cambridge, MA 02138 \\ January 2017
}

We thank Paul Bingley, Dalton Conley, John Donohue, Jens Ludwig, Justin McCrary, Joe Price, and numerous seminar participants at the Danish Institute for Local and Regional Government Research, NBER Summer Institute Economics of Crime Workshop, CESifo Economics of Education Group Conference, University of Essex and University of Notre Dame. We are grateful to the Florida Departments of Education and Health for providing the de-identified, matched data used in this analysis. Breining gratefully acknowledges financial support from CIRRAU and Danish Council for Independent Research. Figlio appreciates funding from the U.S. Department of Education, the National Institutes of Health, and the Bill and Melinda Gates Foundation. The conclusions expressed in this paper are those of the authors and do not represent the positions of the Florida Departments of Education and Health, nor those of our funders, nor those of the National Bureau of Economic Research.

NBER working papers are circulated for discussion and comment purposes. They have not been peer-reviewed or been subject to the review by the NBER Board of Directors that accompanies official NBER publications.

(C) 2017 by Sanni N. Breining, Joseph J. Doyle, Jr., David N. Figlio, Krzysztof Karbownik, and Jeffrey Roth. All rights reserved. Short sections of text, not to exceed two paragraphs, may be quoted without explicit permission provided that full credit, including $(\odot)$ notice, is given to the source. 
Birth Order and Delinquency: Evidence from Denmark and Florida

Sanni N. Breining, Joseph J. Doyle, Jr., David N. Figlio, Krzysztof Karbownik, and Jeffrey

Roth

NBER Working Paper No. 23038

January 2017

JEL No. J01

\begin{abstract}
$\underline{\text { ABSTRACT }}$
Birth order has been found to have a surprisingly large influence on educational attainment, yet much less is known about the role of birth order on delinquency outcomes such as disciplinary problems in school, juvenile delinquency, and adult crime: outcomes that carry significant negative externalities. This paper uses particularly rich datasets from Denmark and the state of Florida to examine these outcomes and explore potential mechanisms. Despite large differences in environments across the two areas, we find remarkably consistent results: in families with two or more children, second-born boys are on the order of 20 to 40 percent more likely to be disciplined in school and enter the criminal justice system compared to first-born boys even when we compare siblings. The data allow us to examine a range of potential mechanisms, and the evidence rules out differences in health at birth and the quality of schools chosen for children. We do find that parental time investment measured by time out of the labor force is higher for firstborns at ages 2-4, suggesting that the arrival of a second-born child extends early-childhood parental investments for first-borns.
\end{abstract}

\author{
Sanni N. Breining \\ Department of Economics and Business Economics \\ Aarhus University \\ Fuglesangs Alle 4 \\ 8210 Aarhus V \\ Denmark \\ snbreining@gmail.com \\ Joseph J. Doyle, Jr. \\ MIT Sloan School of Management \\ 100 Main Street, E62-516 \\ Cambridge, MA 02142 \\ and NBER \\ jjdoyle@mit.edu \\ David N. Figlio \\ Institute for Policy Research \\ Northwestern University \\ 2040 Sheridan Road \\ Evanston, IL 60208 \\ and NBER \\ figlio@northwestern.edu
}

Krzysztof Karbownik

Institute for Policy Research

Northwestern University

2040 Sheridan Road

Evanston, IL 60208

krzysztof.karbownik@northwestern.edu

Jeffrey Roth

Department of Pediatrics

University of Florida

PO Box 100296

Gainesville, FL 32610-0296

jeffroth@ufl.edu 


\section{Introduction}

Economists and policy makers have long been interested in the production function for human capital, with increasing attention paid to the development of non-cognitive skills (Cunha et al. 2010; Conti et al. 2016). Delinquency is a welfare-relevant manifestation of lower-level acquisition of noncognitive skills. At young ages, disruptive peers have been shown to significantly impair learning (Carrell and Hoekstra 2010; Carrell et al. 2016; Kristoffersen et al. 2014). At older ages, crime incurs direct harm on others as well as significant investments to deter and punish criminal activity (Nagin 2013). A better understanding of the causes of crime would inform policies aimed at preventing delinquency in the first place.

The family environment plays a major role in the development of these non-cognitive skills and subsequent delinquency. Widom (1989) discusses a "cycle of violence" where delinquency among parents is passed on to children. The sheer amount of time children spend with their family and the influences each member has on one another imply that the family must have large effects; however estimating effects of parental investments and sibling influences can be confounded by endogeneity concerns.

This paper studies the effects of family environment on child delinquency outcomes through the lens of the influence of birth order across siblings. There is a long history of studying birth order in social psychology and economics (see, for example, Adler (1928), Behrman and Taubman (1986) or Sulloway (1996)). The main recent empirical contributions stem from work by Black, Devereux and Salvanes (BDS). Their 2005 study employed large datasets from Norway for outcomes measured from 1986-2000, and they find large birth order effects on child outcomes that appear to dominate those associated with family size. Using between and within-family variation in birth order, laterborn children achieve a lower level of educational attainment and have worse labor-market outcomes. They also find a higher likelihood of teen births among women. Our work complements theirs by bringing to bear evidence on important outcomes rarely explored in the literature, with data from two very different settings.

In particular, this paper offers three main contributions. First, we provide some of the first estimates of the effects of birth order on delinquency behavior - disciplinary actions and truancy at school, juvenile delinquency, and adult crime and imprisonment - that make use of large-scale data and facilitate sibling contrasts. A second innovation is that we study these relationships in two very different environments: Denmark and the state of Florida. Using the same empirical framework, variation in results (or lack thereof) across these environments provides insights into whether the effects stem from particular institutions or are more general in their nature. Third, using especially rich register data in Denmark and linked administrative data in Florida, we are able to investigate potential mechanisms for such differences. This information includes measures of infant and childhood health, parental investments, school quality and sibling composition.

Across both of our locations, and across different estimation techniques, we find that second-born boys are substantially more likely to exhibit delinquency problems compared to their older sibling. In particular, involvement with the juvenile justice system is found to be on the order of 40 percent 
higher than the mean for first-born boys in both Denmark and Florida. Incarceration by age 21 is also found to be 40 percent higher in Denmark. These effects are particularly strong among more severe violent crimes (36 percent). In Florida, similarly large effects are found for suspensions in school (29 percent) but effects on truancy are much more moderate and heterogeneous. We find corroborative evidence when we consider a sample of young adolescents in Denmark where we can measure behavioral problems directly in the form of hyperactivity and measures of conduct problems by age 12 .

In terms of mechanisms, we can rule out large classes of explanations. These include worse health at birth (second-born children appear healthier) or in childhood (second-born children have fewer disabilities), schooling decisions including the age of entry and the quality of schools chosen (secondborn children attend no worse schools and are more likely to attend pre-kindergarten and daycare) as well as maternal employment (measured by maternity leave) in the first year of life. We do find that maternal employment and the use of daycare is higher for second-borns in years 2-4 compared to older siblings. While it is well known that first-borns have undivided attention until the arrival of the second-born, these results show that the arrival of the second-born child has the potential to extend the early-childhood parental investment in the first-born child and a concomitant bifurcation of parental attention between first- and second-born children. We also consider test score outcomes in both Denmark and Florida, and find that second-born boys in comparison to their older siblings score lower on reading and math assessments in Denmark but only on reading test in Florida.

The remainder of the paper is organized as follows. Section 2 provides a brief background on the previous literature with an emphasis on the areas where our results represent a contribution. Section 3 describes the data. Section 4 presents the empirical framework. Section 5 reports the main results, mechanisms heterogeneity and robustness checks. Section 6 concludes.

\section{Background}

\subsection{Previous evidence on birth order and delinquency}

Previous work focusing on delinquency has employed survey data from the National Longitudinal Study of Adolescent Health (Argys et al. 2006; Averett et al. 2011; Cundiff 2013). These studies tend to find modest to no evidence of increased crime associated with birth order, along with substance use and sexual activity. For example, Cundiff (2013) uses Add Health data and finds that selfreported delinquency - a composite measure including marijuana use, non-violent crime, and binge drinking - is not related to birth order in regression models that include family fixed effects. Silles (2010) studies the National Child Development Study - a study of children born in one week in 1958 in the UK and followed afterward - and finds that first-born (and last-born) children have improved non-cognitive test scores. Unfortunately, it is difficult to estimate family fixed-effects models with precision in these survey datasets. For example, Cundiff (2013) includes 655 families, and the odds ratio for delinquency is relatively imprecise ( 0.86 - 1.52 for middle-born compared to first-born). The current paper relies on much larger administrative datasets that provide more precision when 
using within-family variation in birth order to compare siblings.

\subsection{Potential mechanisms}

While birth order effects in education and labor market outcomes have been explored, the mechanisms behind these results have not been studied extensively. One potential explanation offered for such effects is different levels of parental investments across children. A standard economic model that reconciles fertility and parental investment in children is the so-called "quantity-quality tradeoff" proposed by Becker (1960), and further developed in Becker and Lewis (1973) and Becker and Tomes (1976). It is based on the premise of negative correlation between the number of children and income of the parents originating from rising marginal cost of quality with respect to quantity. In other words, with each additional child it is more expensive to maintain the same "quality" of children, and thus parents are going to invest less in human capital of higher birth order children (Galor and Weil 2000). ${ }^{1}$ More recent literature has found mixed evidence on the "quantity-quality tradeoff" (Black et al. 2005; Angrist et al. 2010; Mogstad and Wiswall 2016).

Empirically, parental time investments are found to be lower for later-born children, as the first-born has some undivided attention from parents until a younger sibling arrives (Price 2008). ${ }^{2}$ Averett et al. (2011) find that first-born children are supervised more and have fewer risky behaviors. Lehmann et al. (2014) also use NLSY data and show that birth order effects on parental-investment measures appear to be present at ages 0-2 and grow until ages 5-6 when schooling may mitigate such effects. Interestingly, the paper reports a broad shift in parenting for later-born children: parents are more likely to miss prenatal visits, less likely to abstain from alcohol during pregnancy and breastfeed, and parents provide less early-cognitive stimulation at home. Another direct measure of parental investment is in the form of financial transfers, and de Haan (2010) used the Wisconsin Longitudinal Study to show that such transfers are higher for earlier born children.

A second explanation is the influence that siblings have on one another: the quintessential peer effect. Later children, unlike first-borns, will have older siblings as role models (Zajonc and Markus 1975). In addition, older siblings may also benefit from teaching younger siblings and acting as such a role model (Smith 1993). These peer effects are difficult to isolate due to the simultaneity of influences (Manski 1995; Joensen and Nielsen 2015; Black et al. 2016). There is also a literature on the influence of sibling composition (brothers vs sisters) on educational attainment. Butcher and Case (1994) found that the presence of brothers historically increased educational attainment of women, although there is mixed empirical evidence for these effects with some studies finding no effects and others finding opposite effects (Hauser and Kuo 1998; Kaestner 1997; Conley 2000;

\footnotetext{
${ }^{1}$ An alternative model of the family that can explain birth-order differences is offered by Hotz and Pantano (2015) who argue that parental reputation concerns could lead to more intense monitoring and discipline among older children as a signal to later born children, and this could lead to direct effects on first-borns such as superior performance at school and better behavior. Sulloway (1996) presents a related argument, that first-born children may be more likely to identify with their parents and therefore to emulate and obey their parents in order to gain parental attention.

${ }^{2}$ Price (2008) investigated American Time Use Survey and found that first-borns get 20-30 minutes more quality time each day compared to second-born in a similar family. This appears to be due to equalizing time after the secondborn arrives even thought the first-born had undivided attention when there was only one child in the household.
} 
Deschenes 2002; Dayioglu et al. 2009; Chen et al. 2009).

\section{Data description}

\subsection{Denmark}

For Denmark, the key data source is the Danish Birth Register, which includes information on individuals born in the period 1960-2010. For each child, the dataset includes information on exact date of birth and various birth outcomes. A unique identification number enables us to link generations, hence children can be linked to their parents and siblings. Given this structure of the data and access to the specific date of birth, we can measure each individual's birth order, the completed family size and the sex composition of children in the family.

The unique identifiers also allow us to match the birth records to rich data from various administrative registers. This provides us with demographic characteristics of the parents such as age, educational attainment, labor market status, earnings and immigrant status.

Our primary outcomes reflect delinquency behavior. To characterize such behavior in the Danish context we exploit access to the Criminal Registers including convictions, suspended prison sentences and incarceration, date of crime as well as type of crime. In Denmark, from the age of 15 an individual is considered fully responsible for any criminal act, and we can observe all criminal convictions from that age onward. Our main measure of risky behavior at the youngest age is an indicator of having any criminal convictions by age 16, and we also consider having any criminal convictions by age 21. As a more severe measure of crime we also consider having ever been issued suspended or implemented imprisonment sentence by those ages. All outcome variables are multiplied by 100 to obtain percent values. Our data also allow us to explore effects at other ages, and across different types of crimes.

To obtain a measure of school performance we study data from the School Registers. In Denmark the typical child enters first grade of compulsory schooling education the year they turn seven. ${ }^{3}$ Compulsory school is completed with a ninth grade exit exam. ${ }^{4}$ We measure school performance as ninth grade exit exam grades in reading and math. These exam results are based on assessments by the student's teacher and by an external reviewer. All grades are standardized to have zero mean and unit standard deviation within each cohort.

In addition to the delinquency outcomes, we explore potential mechanisms that can explain the birth order effects. One goal is to explore outcomes across a range of ages in an effort to determine when differences across siblings begin to occur. First, we consider conditions surrounding the birth of the child to measure the health endowed to the child which is partly due to prenatal investments. Specifically we consider birth weight and whether the mother experienced any complications during the pregnancy.

\footnotetext{
${ }^{3} \mathrm{~A}$ few children may be one year younger and a few may be one year older; we also consider school starting age as an outcome.

${ }^{4}$ The Danish educational system is publicly funded from primary school throughout college. No tuition is charged and once the student turns 18 he or she is offered monthly financial aid from the government.
} 
Second, we consider maternal investments early in a child's life. This includes information about days the mother spent on maternity leave along with information on maternal employment status 0-10 years after childbirth. From the Register of Daycare Institutions we obtain information about the populations' use of daycare facilities. Each year between 1995 and 2008 we have information about its type and place, and we create a measure of enrollment into out-of-home daycare at ages $1-3$.

Next, we add a measure of school starting age to see if parents are treating second-born children differently at that stage of the life cycle. Then we use information from the Danish National Patient Registry and Danish Psychiatric Central Registry. From these data we have information about psychiatric diagnoses of all children diagnosed at a Danish general hospital. We consider two groups of diagnoses: disorders of psychological development as well as behavioral and emotional disorders, and we observe whether the child has received such a diagnosis by age $10 .^{5}$

Finally, we are able to explore measures of non-cognitive skills during childhood. Delinquency can be viewed as a behavioral outcome that is the consequence of lower levels of non-cognitive skill development, and there is evidence of birth order effects on non-cognitive skills (Black et al. 2015; Kaufmann and Messner 2015); however, these studies evaluate non-cognitive skills later in life (at the time of the military draft or by parents), and are not able to measure changes in behaviors that could be related to later life crime such as emotional, hyperactivity and conduct problems. The Danish data, on the other hand, provide us with information gathered in the internationallyrecognized Strengths and Difficulties Questionnaire $(\mathrm{SDQ})^{6}$, a behavioral screening questionnaire conducted when children are roughly 12 years old. These data were collected as part of the Danish two-teachers experiment. ${ }^{7}$

The SDQ contains 25 items within five dimensions. Four of the dimensions concerns difficulties covering conduct problems, emotional symptoms, hyperactivity and peer relationships. One dimension concerns strengths and covers prosocial behavior. ${ }^{8}$ In line with past literature, we can use the four difficulty dimensions to generate the Total Difficulty Score reflecting the child's socio-emotional behavior. We follow the SDQ scoring rubric (Goodman et al. 2010) and divide these scores into four categories: close to average, slightly raised, high and very high. Each of these categories will constitute an outcome that we will study in the analysis below. Similarly we split the scores on the fifth dimension, prosocial behavior. These measures will allow us to investigate whether there are

\footnotetext{
${ }^{5}$ Psychological development disorders cover diagnoses classified within the ICD10 codes F80-F89. Behavioral and emotional disorders cover diagnoses classified within the ICD10 codes F90-F98; one of the most frequent diagnoses within this category is ADHD.

${ }^{6}$ The Strengths and Difficulties Questionnaire was first developed by Goodman (1997) and later used in numerous studies (e.g. Currie and Lin 2007; Kelly et al. 2009; Datta Gupta and Simonsen 2010; Berger and Spiess 2011; Kristoffersen et al. 2014).

${ }^{7}$ The experiment was conducted in the 2012-13 school year and took place at the intermediate stage of primary school (6th grade). The sample consists of around 10,000 pupils from 231 public schools across 14 municipalities. If a school is part of the sample all its 6th graders were included. For more information about this data see " $2 \mathrm{~L}$ Rapport Undersøgelse af effekten af tolærerordninger" by Andersen et al. (2014). The survey we are using was conducted before the two-teacher experiment began. Approximately 10,000 sixth grade pupils answered the questions in September 2012. Here they were around 12 years old.

${ }^{8}$ For a detailed list of questions see http://www.sdqinfo.com/.
} 
differences in psychological attributes or non-cognitive skills by birth order in early adolescence.

\section{$3.2 \quad$ Florida}

The Florida Departments of Education and Health merged birth records for all children born in Florida between 1992 and 2002 with school records for the academic years 1995-96 through 2012-13 for the purpose of this research. The Florida agencies matched children along three dimensions: first and last names, date of birth, and social security number. Rather than conducting probabilistic matching, the match was performed such that a child would be considered matched so long as (1) there were no more than two instances of modest inconsistencies, and (2) there were no other children who could plausibly be matched using the same criteria. Common variables excluded from the match were used as checks of match quality. These checks confirmed a very high and clean match rate: In the overall match on the entire population, the sex recorded on birth records disagreed with the sex recorded in school records in about one-one thousandth of one percent of cases, suggesting that these differences are almost surely due to typos in the birth or school records.

Between 1992 and 2002, 2,047,663 births were recorded by the Florida Bureau of Vital Statistics; however, in the current project we can utilize only the 1994 to 2002 births as we are unable to match siblings for the 1992 and 1993 birth cohorts. There were 1,609,470 singleton births in Florida between 1994 and 2002, and of these 1,290,077 children were subsequently observed in Florida public school data, representing an 80.2 percent match rate. The match rate is almost identical to the percentage of children who are born in Florida, reside there until schooling age, and attend public school, as computed using data from the decennial Census and American Community Survey for years 2000 through $2009 .{ }^{9}$ In the school districts representing the vast majority of Florida households, children are matched to households, and we link these anonymized school records back to the relevant students' birth records (via the birth-school link conducted by the Florida Departments of Education and Health) to determine birth order; this backward-matching also allows us to check the likelihood that students we believe to be siblings are actually siblings (e.g., by comparing maternal characteristics such as date of birth).

Florida birth certificates enumerate demographic characteristics of the mother (including education, marital status and place of residence), demographic characteristics of the father if he appears on the birth certificate, and health and demographic characteristics of the newborn. ${ }^{10}$ In particular, we observe birth weight and indicators for any maternal health problems, whether or not they are related to the pregnancy.

Our primary in-school delinquency outcomes are suspensions and truancy. We obtain these measures from administrative school records that are available for the school years from 2002-03 through 2011-12. We measure suspensions as an indicator variable whether the child was ever temporarily removed from school in a given school year, while we measure truancy based on the

\footnotetext{
${ }^{9}$ Figlio et al. (2013) provide extensive validity checks on the matching procedure.

${ }^{10}$ In a very small number of cases (fewer than 100 sibling pairs) where the race or ethnicity of the mother on sibling's birth certificates do not match, we assign the race and ethnicity associated with the birth certificate of the first-born child.
} 
reported absence rate, defined as number of days absent (net of suspended days) in school to total number of days that the child was enrolled in a given school year. ${ }^{11}$ Both variables are multiplied by 100 to obtain percent values. ${ }^{12}$ This results in repeated observations for each student, which will allow us to trace effects across different grades, as described in more detail below.

In addition, the Florida Education Data Warehouse provides us with a wide array of additional outcomes that we use to investigate the mechanisms beyond the identified birth order effects. Our measures of academic performance are based on Florida Comprehensive Assessment Test (FCAT) in mathematics and reading, a state-wide standardized yearly assessment of all students in Florida conducted in grades three through ten. In this paper we focus on test scores in grades three through eight, because curriculum differences make interpersonal test score comparisons relatively difficult in high school (e.g., one tenth grader is taking algebra while the other is enrolled in calculus). Therefore, each child in the sample can contribute up to six observations, one for each grade observation.

Unlike in Denmark, we cannot match children to their medical records in Florida. However, the Florida school records also provide an opportunity to observe poor health outcomes in childhood and adolescence. Specifically, we observe whether each child receives special education services for physical disabilities, such as orthopedic impairments, sensory impairments, and speech pathologies, as well as intellectual and emotional disabilities. These measures are high-quality indicators of some elements of child health as they are linked to school finances and monitored by Florida Department of Education.

While we have limited ability to measure investment in human capital, we can measure one of its components, namely school quality as defined by the state of Florida via its school accountability system. Since 1999, the Florida Department of Education has awarded each of its public schools a letter grade ranging from A (best) to F (worst). Initially, the grading system was based mainly on average proficiency rates on the FCAT standardized exam. Beginning in 2002, grades were based on a combination of average FCAT proficiency rates and average student level FCAT test score gains from year to year; other quality indicators, such as competency in science, were subsequently added. ${ }^{13}$ We utilize this information to construct contemporaneous school quality measure. For ease of implementation, we measure the school letter grades numerically, with A schools receiving 4 points and $\mathrm{F}$ schools receiving 0 points. As additional measures of parental investment in children, we also investigate if the second-born is less likely to attend pre-kindergarten and whether parents hold back the child a year at the start of schooling.

To measure interactions with the juvenile justice system, one large anonymous Florida school

\footnotetext{
${ }^{11}$ Florida law defines a "habitual truant" as a "student who has 15 or more unexcused absences within 90 calendar days with or without the knowledge or consent of the student's parent or guardian". We focus on days absent from school as an indicator of a proclivity toward truancy.

${ }^{12}$ The Florida records also include information on disciplinary referrals that do not result in suspensions, but the statewide referral data only include the most serious disciplinary infractions and therefore include just a subset of all disciplinary incidents; 93 percent of the disciplinary incidents reported in the state records result in suspension. Because we are not entirely certain about the rules governing which non-suspension referrals are included in the data, we concentrate exclusively on disciplinary referrals that result in suspension.

${ }^{13}$ See Rouse et al. (2013) for a detailed description of the over-time changes to Florida's school accountability system.
} 
district reports whether children have been incarcerated in juvenile detention centers. ${ }^{14}$ Between the 1989-90 academic year and the 2004-05 academic year, the school district retained a code in its student master records for whether the student was in a juvenile detention center, and maintained records for that student as long as the student remained registered for school in the district. Florida children are required to remain in school until their sixteenth birthday, so this variable is most complete for children under the age of sixteen. Given the ending date of the records for the juvenile detention code, we can measure juvenile detention through the end of the mandatory school attendance period for children born on or before August 31, 1989. ${ }^{15}$ For the purpose of this juveniledelinquency analysis, we measure whether children are siblings based on whether they are co-resident and have the same last name ${ }^{16}$; since we can begin to measure residential addresses in this county in the 1989-90 academic year, we feel most comfortable about our ability to measure birth order for children born on or after September 1, 1979. ${ }^{17}$ Limiting ourselves to first- and second-borns who were born between September 1, 1979 and August 31, 1989 leaves us with 24,928 children in 12,464 families. In this school district, we cannot measure variables observed on birth certificates, but we are able to observe whether a child is limited English proficient, receives subsidized meals, or lives in a low-income micro-neighborhood.

\subsection{Sample construction}

We construct the analysis samples for both locations in the same way, to the extent possible. As in the previous literature, we exclude twins from the sample because all of the mechanisms for birth order effects that we postulate involve the children being the product of successive pregnancies. Our main analysis will focus on the first two children of families with two or more children, as the previous literature has found that birth order effects are particularly salient for the first two children in a family. Further, given our emphasis on delinquency outcomes we focus on families where the secondborn child is a boy. The main analysis sample is also restricted to full biological siblings meaning that all the children have the same mother and father so that we can exploit variation within these stable families by comparing outcomes across siblings. ${ }^{18}$ We present results for second-born girls, and for other types of families, as separate investigations later in the paper.

Table 1 reports summary statistics for all families, all families with two or more children where the first two children are full biological siblings, and our main analysis sample. In Denmark, the family characteristics are very similar across these samples, with mother's age at first birth moderately

\footnotetext{
${ }^{14}$ School districts in Florida are county-level. We are unable to link the Florida statewide school records to juvenile crime data, and the children in the matched birth-schools data are too young to measure juvenile crime for many sibling pairs in any event.

${ }^{15}$ September $1^{\text {st }}$ is the typical cutoff for school attendance in any given year.

${ }^{16}$ We have also relaxed this definition of sibship to look at consistently coresident children with different last names, and continue to find similar results, but we prefer the same-name definition because we are most confident there that the children are full siblings.

${ }^{17}$ With this restriction, we will only miscode birth order for families with more than a six year gap between older siblings and the oldest-observed children enrolled in school in 1989-90.

${ }^{18}$ In Denmark we observe complete information on fathers in 98 percent of sibling population and father is the same in 92 percent of families with first two born siblings. In Florida we observe complete information on fathers in 79 percent of sibling population and father is the same in 70 percent of families with first two born siblings.
} 
lower for families with 2 or more children compared to all families. In Florida, families with 2 or more children have higher educated mothers, come from higher income ZIP codes, and are more likely to be white. These differences are largely due to the restriction that siblings have the same father. For example, if we study all mothers with two or more children irrespective of the father status then the fraction of African American mothers increases to 22 percent.

One of the main contributions of the paper is that we can compare birth order effects using the same types of model specifications and similar outcome measures across two very different environments. Table 1 shows that there are clear differences in the observables between Denmark and Florida. The average age at first birth in Denmark is lower than in Florida by about one year. Within the sample of two or more children the spacing between first- and second-born is bigger in Denmark than in Florida. The education systems are different, but in Denmark, 32 percent of mothers have a basic education that ends after 9 years and 23 percent have a college degree, whereas in Florida 10 percent of mothers in our analysis sample are high school dropouts and 31 percent have a college degree. ${ }^{19}$

Florida has much more racial-ethnic variation than Denmark, and although race or ethnicity are not reported in the Danish Registers, national statistics reveal that 8.9 percent of people living in Denmark are immigrants, and of these 58 percent originate from non-western countries. There is a negligible fraction of immigrants of Hispanic origin. In contrast 22 percent of mothers in Florida are African American and 24 percent are of Hispanic origin. Finally, the fraction of immigrants is twice as high in Florida as it is in Denmark, and furthermore the sources of immigration differ. In Denmark immigrants come mostly from Turkey, Iraq, Bosnia-Herzegovina, Iran, and Pakistan. In Florida the most frequently-occurring countries are Cuba, Mexico, Colombia, Venezuela, and the Dominican Republic, but in addition, 44 percent of immigrants to Florida come from non-Hispanic countries in the Caribbean, Europe, Asia, and Africa.

The last panel of Table 1 reports means for the outcome variables. Interactions with justice system are not uncommon, and in Denmark by age 21 nearly 11 percent of individuals have a conviction, 4.2 percent are given suspended prison sentences and 1.4 percent are actually incarcerated. ${ }^{20}$ When we focus on boy-boy and girl-boy families these rates are somewhat higher. In Florida, 5.6 percent of our analysis sample is suspended and the absence rate is 3.8 percent.

\section{Empirical model}

The main estimating equations for person $i$ born in cohort $c(i)$ in family $f(i)$ are of the form:

$$
Y_{i}=\beta_{0}+\beta_{1} \operatorname{Second}_{i}+\beta_{2} \operatorname{Girl}_{i}+\beta_{3} X_{i}+\delta_{c(i)}+\mu_{f(i)}+\varepsilon_{i}
$$

\footnotetext{
${ }^{19}$ In about 10 percent of cases we do not observe maternal and paternal education in Denmark. Similarly we do not observe maternal and paternal employment in 9 percent of cases. In OLS regressions where we use these variables as controls we impute mean values and create an indicator variable for missing education and/or employment.

${ }^{20}$ We exclude all traffic offenses to focus on more serious offenses. Our data on convictions are very similar to national statistics and we under-count between 12 and 20 percent of suspended and implemented incarceration sentences (Statistik). This undercounting is likely driven by the selected sample of families that we include in our final analysis.
} 
where $\beta_{1}$ compares second-born boys to their older sibling, $\beta_{2}$ is an intercept shift for girls in girl-boy families, $X$ contains controls described below, $\delta_{c}$ are cohort effects included to control for the possibility that secular trends in population-level student performance might confound birth order estimates, and $\mu_{f}$ are family fixed effects to exploit within-family variation. The fixed effects are appealing because they control for factors that are invariant within families, and we are particularly interested in comparing siblings. In practice, previous work suggests that family fixed effects do not have a large impact on estimates (Black et al. 2005; Bagger et al. 2013; Härkönen 2014). A cost of within-family estimation is that standard errors can increase, but with our large samples precision is not particularly problematic. We report results with and without family fixed effects, and when we exclude them our vector of $\beta_{3}$ contains estimates on mother and father age at birth and education, marital status and immigrant status indicators as well as regional controls (ZIP codes - 1,472 in total - for Florida and municipalities - 275 in total - for Denmark). In Denmark we further include maternal and paternal employment, family income and number of children until 2011 as a measure of completed family size, while in Florida we include race and ethnicity indicators. ${ }^{21}$ We cluster standard errors at the family level.

In the Florida school records we observe individual students multiple times between grades one (three) and eight. Since we want to observe children longitudinally as they age, we impose a longitudinal component into the observed grades. Namely, we start with observations in grade one and then assign children to subsequent "imputed grade levels" with each school year, which allows us to account for grade repeaters. In the main results we pool all the student observations together and in Figures 2, 3 and 5 we present estimates as children progress through schooling, scaling the estimates, except for test scores, by the baseline first-born boy mean for each imputed grade. ${ }^{22}$

In the Florida juvenile-delinquency data, we can include an indicator for (first observed) limited English proficiency, subsidized school meal status (a common measure of socio-economic status), and average school meal status in student micro-neighborhood. This latter variable is possible because the school district divides the county into over 1,000 micro-neighborhoods for the purposes of school assignment and school bus routing and scheduling. While the neighborhoods vary in size, on average between 50 and 200 students live in a micro-neighborhood at any given time. ${ }^{23}$

One estimation concern is that family structure can have its own effects on a family other than direct birth order effects. Bagger et al. (2013) note that birth order and family size are jointly determined. That is, one cannot manipulate family size, holding within-family distribution of birth orders constant. Another example is that families with same-sex children among their first-borns are more likely to have additional births - a measure that is often used as an instrument for family

\footnotetext{
${ }^{21}$ In Denmark maternal and paternal employment as well as family income are measured in the year before birth. Our fixed effects results hold also when we include time varying family controls such as mother's age, education and marital status as well as zip code/municipality of residence.

${ }^{22}$ In Florida we observe test scores for grades three through eight, and thus in Table 6 we restrict our attention to these grades only. We observe suspensions and truancy in grades one through eight for birth cohorts 1994 to 2000 while three through eight for birth cohorts 2001 and 2002. We construct the imputed longitudinal grade starting in the first observed grade in these samples. The results are robust to restricting the delinquency measures to grades three through eight.

${ }^{23}$ Specific numbers are not provided here in order to preserve the anonymity of the school district in question.
} 
size (Angrist et al. 2010; Conley and Glauber 2006). Black et al. (2005) also use this instrument in their analysis of family size, but they note that (1) same-sex siblings may have an independent effect on child outcomes and (2) that the birth order effects are stable when instrumenting for completed family size. To address these issues, we will show results with and without controls for completed family size. We will also report results for different sex compositions that drive the instrument for family size used in the literature. This serves as both a robustness check and an exploration of sibling influences under the assumption that same-sex siblings have more influence on one another compared to mixed-sex siblings.

Another issue is that last-born children may have worse outcomes when families decide not to continue having children if they have one that is particularly costly e.g. has health problems (Ejrnæs and Portner 2004). Our main analysis includes families with two or more children, and we also examine results in families with three or more children so that the second-born is not the last born.

\section{Main results}

This section first reports results for delinquency outcomes (Table 2), which is then followed with the analysis of different types of criminal activity in Denmark (Table 3). Table 4 presents short-run noncognitive outcomes at age 12 in Denmark while Table 5 investigates early childhood mechanisms. We then present short-run cognitive outcomes, namely test scores in Table 6. Subsequent tables further examine potential mechanisms and heterogeneity focusing on spacing between siblings (Table 7), maternal education (Table 8), contrast between native born and immigrant parents (Table 9), and finally for Florida on racial and ethnic contrasts (Table 10).

\subsection{Delinquency}

Table 2 reports our main results for delinquency. Panels A, B and C show results for Denmark, where second-born boys are more likely to have criminal-justice involvement and serve time in prison both by age 16 and 21. In models with family fixed effects, second-born boys are 1.6 percentage-points more likely to have been found convicted of a crime when aged 15 or 16 compared to first-borns. This is 35 percent higher than first-born boys. By age 21, the estimate suggests a 3.6 percentage-points increase, or 22 percent higher than the mean for first-born boys. These results are fairly stable in OLS models both with and without extensive controls, and in models with family fixed effects. The early-age result grows somewhat in magnitude when we include family fixed effects. The larger effect (compared to the mean) at younger ages when crime is less common is consistent with birth order effects having particularly strong influences for the extremes of the behavioral distribution. We document this phenomenon in Figure 1, which depict elevated effects on criminal activity for ages 16 to 18 that subsequently stabilize for all outcomes.

When we look at more serious crimes - those that yield a prison sentence - the means of the dependent variables for first-born boys are 0.1 and 1.0 percent by age 16, and 2.7 and 7.2 percent 
by age 21 for implemented and suspended sentences, respectively. By age 21, Table 2 shows that second-born boys are found to be 1.1 and 2.4 percentage-points more likely to have spent time or be sentenced to spending time in prison, respectively, which implies 40 and 33 percent effects. These are very large effects given that we are using within-family variation.

Panel D of Table 2 provides analogous results for juvenile-delinquency by age 16 in a single, large anonymous county in Florida. In the OLS model without family fixed effects but with a wider set of controls, second-born boys are 0.5 percentage-points more likely to become involved with the juvenile justice system, which is approximately 21 percent higher than the mean for first-born boys. When we focus on within-family comparisons by adding family fixed effects, the estimate increases to 1.1 percentage-points, or 42 percent. Notably, even though as documented in Table 1 the state of Florida is very different from Denmark in terms of observable socio-demographic characteristics as well as the judicial systems, the estimated effects of being born second are remarkably similar across the two locations.

Another measure of behavioral issues can be found in the Florida schooling data in the form of suspensions and absences. We define these as an indicator for being ever suspended and the absence rate in a given school year multiplied by 100. Remarkably, we find similar results for suspensions as they are 1.7-4.3 percentage-points higher (or 29-72 percent higher than the mean for first-born boys). For absences, we find point estimates of 0.01 to 0.35 percentage-points more absences from school, or 0.2 to 9.4 percent higher. For suspensions, similar to the criminal activity results, we document moderately larger second-born effects earlier in life, namely in elementary school in comparison to middle school (left panel of Figure 2). This pattern is not confirmed for absence rates (right panel of Figure 2), however, where we observe fewer absences for the youngest grades, and more absences among second-borns in grades 4, 5 and $8 .{ }^{24}$ This could be explained by the fact that in early schooling years absenteeism is much more related to health and acclimatization to education processes than intentionally missing classes: a sign of misconduct in later grades that corroborates the delinquency findings. ${ }^{25}$

For the delinquency outcomes measured in Florida schooling data, adding family fixed effects reduces the point estimates. One explanation is that the set of controls varies across panels D and E due to data availability. Given that there are meaningful controls at our disposal in both settings, however, the fact that they increase point estimates for some outcomes but decrease point estimates for others helps to rule out straightforward explanations that the results are due to omitted variable bias that operates in a similar way across outcomes. In any event, we favor the within-family comparison including family fixed effects to absorb time-invariant characteristics of families and we proceed with it throughout the subsequent sections of the paper. ${ }^{26}$

\footnotetext{
${ }^{24}$ Approximately zero effects documented in Table 2 are driven by this heterogeneity over time as the negative early schooling coefficients cancel out with positive coefficients is grades 4,5 and 8 . Thus in subsequent tables we mostly focus on truancy in grades 4 to 8 .

${ }^{25}$ The early grades results are less negative and the later grades results are more positive for absences when we estimate OLS regressions with or without controls, and thus in Table 2 in columns (4) and (5) of panel E we estimate positive and significant coefficients. This discrepancy supports the need for within and across families comparison rather than just across families comparison.

${ }^{26}$ Even though at each grade we compare individuals from the same family, across grades we have a repeated
} 
The uniqueness of Danish registry data allows us to investigate different types of crime. If our working hypothesis about decreased non-cognitive abilities that affect particularly extreme parts of the distribution is correct then we should see larger birth order effects for more severe rather than petty crimes. Table 3 reports the results for violent crime (e.g. manslaughter, rape or death threats), property crime (e.g. forgery, arson or burglary) and special crime (e.g. drug offenses, illegal weapon possession or human trafficking) convictions. First as expected, convictions rate is the highest for property crimes, followed by special crimes and lowest for violent crimes. However, the second-born effects are the largest among the latter group which supports our hypothesis on particularly strong influences for the extreme outcomes.

\subsection{Non-cognitive measures}

In addition to measures of delinquency, we are able to study the relationships between birth order and measures of non-cognitive skills observed as part of the Strengths and Difficulties Questionnaire (SDQ), measured at approximately age twelve for a subset of the Danish population of children. One limitation of this data set is that we cannot implement family fixed effects strategy due to observations on only three cohorts in selected schools. Therefore, we present OLS estimates with a rich set of controls including child birth year dummies, mother's age at first birth, mother's age, father's age, municipality dummies, maternal and paternal education, maternal and paternal employment, family income, immigrant dummy, and number of children in family.

Tables 4 and A1 present the results. Panel A of Table 4 presents total difficulties score, and we show its sub-components - emotional, conducts, hyperactivity and peer problems - in panels A to D of Table A1. In panel B of Table 4 we present a positive outcome, namely prosociality score.

Second-born boys are about 5 percent less likely to be categorized as close to average in comparison to their older siblings and although insignificant we find positive coefficients on all the remaining categories of total difficulty score. Investigation of the sub-components of the total score reveals that second-born boys are particularly adversely affected in terms of hyperactivity. They are 4.9 percentage-points less likely to score "close to average" on the hyperactivity component. At the same time, we do not find any statistically significant effects for emotional problems, conduct problems,peer problems and prosocial behavior. Relating this to Heckman (2000) findings of noncognitive skills being important determinants of success, these increased hyperactivity problems may be precursors to criminal-justice involvement later in life (Heller et al. 2015).

\subsection{Mechanisms: Early-life measures}

Our first set of potential mechanisms investigates what happens to these children prior to attending school, and we present the effects of birth order on maternal, infant and childhood health as well as probing into several parental investment channels including differential labor supply responses or

cross-section of families i.e. not all pairs utilized in grade one comparisons are old enough to make it to grade eight comparisons. Due to data restriction we are underpowered to run this panel analysis, however when we restrict the sample to grades one to six then our results are qualitatively consistent with the repeated-cross section estimates for these grades. 
school choices. If we find meaningful effects at these younger ages, this provides some insights into the timing of when differences begin to appear.

Table 5 presents the results. Columns (1) and (2) consider birth weight and complications in pregnancy as measures of the health endowment at birth and proxy for maternal health during pregnancy. Here we find that second-borns weigh 3.7 percent more on average in Denmark and 2.6 percent more in Florida. Similarly, second-borns have fewer complications during pregnancy compared to first-borns (20 percent lower in Denmark, 12 percent lower in Florida). These differences are not explained by the fact that mothers are older for second-born births. ${ }^{27}$ This result suggests that second-borns are not starting out in worse health compared to their older sibling, ruling out one potential mechanism. This is consistent with work by Lundberg and Svaleryd (2016) who find that early life health measures such as hospitalizations are higher among first-borns in Sweden.

Next we consider parental time investment in the form of daycare/preschool and maternal employment. We find that daycare at age 1 is 17 percentage-points lower in Denmark for second-born boys (Table A2). However by age 2 and 3 second-born boys are 3.4 and 10.8 percentage-points more likely to be enrolled in out-of-home daycare ( 5 and 14 percent higher than the mean for first-born boys). This finding corresponds well with maternal employment effects, which we depict in Figure 4 for 0 to 10 years after child birth. It shows that 2-4 years after birth mothers of second-born boys are significantly more likely to be employed compared to mothers of first-borns. The net effect of substituting maternal care with institutional care is ambiguous, however, and in fact earlier return to the labor market may be harmful for boys (Fan et al. 2015). We additionally document that maternity leave is modestly shorter for second-born boys compared to the first-borns -8.6 fewer days of maternity leave compared to a mean of 150 days for first-born boys yields about 6 percent effect. It thus appears that the addition of a second-born child results in mothers spending more of a first-born's early childhood out of the of labor force: maternity leave upon the arrival of a second-born adds time that mothers spend with first-borns in addition to the undivided attention received by first-borns in their first year of life.

In Florida we cannot observe maternal employment or maternity leave uptake but we do observe pre-kindergarten participation, which can begin as early as age two. We define our outcome variable as either parents declaring pre-kindergarten attendance of their children at the time of kindergarten enrollment or actually observing children being enrolled in public pre-kindergarten. We find nearly 7 percentage-points higher participation rate among second-born boys, which is equivalent to 12 percent effect. This finding could indicate a reduction in direct parental investment in favor of institutionalized care but pre-kindergarten participation is generally viewed in the literature as a positive investment in human capital (Havnes and Mogstad 2011).

In terms of school starting age, we see a 3.5 percent decrease in age at first grade in Denmark;

\footnotetext{
${ }^{27}$ There is a positive relationship between maternal age and birth weight when we regress log birth weight on maternal age even if we include family fixed effects, however the main results do not change when we add controls for maternal age at birth. We have also investigated several other birth outcomes, and we find positive effects for birth weight in levels, one and five minutes Apgar scores; negative effects for probability of being low birth weight and being preterm; and no significant effect for abnormal conditions at birth or congenital anomalies. These results are qualitatively similar in both Denmark and Florida.
} 
however, we do not document any elevated probability of being held back in first grade in Florida. Given that the evidence on school starting age and age at testing are mixed, we view our estimates as rather not supporting the lower investment in second-born children. ${ }^{28}$ In fact, it seems that second-born boys in Florida are initially attending higher quality primary schools in comparison to their older siblings, however, the school quality gradient changes as children progress through schooling, and in subsequent grades we observe a mix of positive and negative coefficients generally oscillating around zero (Figure 5). Thus, lower quality schools located in less-affluent neighborhoods should not explain a large part of our delinquency results.

Both data sets allow us to also investigate childhood health as measured by various disabilities. About 18 percent of school age children in Florida are diagnosed with some form of disability, and in our sibling sample we observe 6.8 percent and 6.9 percent of first-born boys having been diagnosed with cognitive and behavioral disability, respectively. The incidence of disability diagnoses in Denmark in far lower with about 2.4 percent on average. Columns (7) and (8) in Table 5 document no birth order gradient in either developmental or behavioral disabilities for both locations, and if anything, we actually see a decreased probability of second-born being diagnosed with cognitive disability in Florida. ${ }^{29}$

One innovation in the current paper is that we are able to explore a wide range of potential alternative mechanisms, including health endowments at birth, parental investment in the form of maternal employment and the use of daycare, as well as school choice. While we do not find the primary mechanism that results in the higher delinquency outcomes later in life, we do find relatively precise zero results on some of these measures. On others we find decreased direct parental investment in the form of time spent with parents in favor of indirect investment in the form of formal childcare arrangements. Whether and how these differences could affect observed later life gaps is an open research question. This leaves us with parental investments within the home (as opposed to time out of the home and in the labor force) and sibling influences as our leading explanations for the birth order results. ${ }^{30}$

\subsection{Test scores}

Our next set of results considers childhood test scores. These are of interest in their own right as educational outcomes, and indeed have been studied in the previous literature. We are also

\footnotetext{
${ }^{28}$ Black et al. (2011) document small positive effects of starting school younger but much larger negative effects of age at test. On the other hand, they also document that boys starting schooling younger have higher incidence of mental health problems at age 18. The school starting age effects are generally relatively small and thus should not be the main drivers of our birth order effects in Denmark.

${ }^{29}$ In the case of Denmark we have also investigated addiction-related hospitalizations by either age 16 or 21 , which include poisoning by narcotics or psychodysleptics or toxic effects of alcohol. We do not find any birth order gaps in these hospitalization outcome rates. Similarly we do not find differences between second-born boys and their older siblings in the probability of dying by either 16 or 21 . Finally, we looked at the number of emergency room visits by age 5 and 10. For both of these outcomes we find that second-born boys have about 10 percent more visits than their older siblings; however, we are unable to distinguish if these are due to poorer underlying health or more accidents related to e.g. increased hyperactivity documented in Table A1.

${ }^{30}$ Buckles and Munnich (2012) document that a one-year increase in spacing increases test scores for older siblings by about $0.17 \mathrm{SD}$, which is comparable to their birth order effect. The paper does not consider delinquency outcomes.
} 
interested in them to investigate whether the behavioral differences identified in our main results are also evident in these measures that are more traditionally thought of as measures of cognitive skills. In Denmark, we observe them for 9th grade, so slightly younger than our crime by age 16 results, and in Florida we have results for younger children - grades 3-8 - so as early as age 8. If we find effects at these younger ages, this trend provides some insights into the timing of when differences begin to appear, and also whether they grow or shrink as children age.

Table 6 shows that in Denmark, second-born boys have lower test scores: 0.11 and 0.14 standard deviations for math and reading, respectively. In Florida, we do not find a birth-order effect for math scores, but we do find that reading scores are 0.08 standard deviations lower for second-born boys. When we look at each grade separately (Figure 3), we find that the positive but insignificant estimate for mathematics is driven by early grades. In fact, for grades three and four we find positive and statistically significant effects of being the second-born. This result would be consistent with the higher early investment into cognitive skills of second-born boys that fades out over time, allowing the non-cognitive aspects to dominate. For reading we observe negative estimates in all studied grades that, except for grade 8 , are relatively constant over time.

\subsection{Heterogeneous delinquency effects}

We have documented very similar effects of birth order on delinquency in both Denmark and Florida; however, the richness of the data in both locations allows us to investigate heterogeneity of these effects in much more detail. We divide this analysis into two parts. First, we continue to consider potential mechanisms through spacing and sex composition of the sibship. Investigation of distance between siblings in terms of age and sex could provide us with some clues about implicit differential investments related to the nature of family arrangements. Second, we investigate if the birth order effects are different in more versus less advantaged families - this is proxied by education, maternal employment (only Denmark), nativity as well as race and ethnicity (only Florida).

We begin by presenting in Table 7 the differential effects of birth order by spacing between firstand second-born children in our data. We divide families into those that had the second birth up to two years after the first one and those where the distance in age between siblings is three years or more. ${ }^{31}$ We find that in both locations delinquency is generally higher among families where the children are closer in age. That said, there are differences in the relative magnitudes of the birth order effects by spacing groups in Denmark versus Florida. In Denmark we find larger birth order effects for the closer spaced siblings while in Florida we find that sibling pairs with longer spacing duration have relatively larger birth order effects. We are underpowered to detect statistically significant birth order effects by spacing in the unnamed Florida county where we observe juvenile justice system interactions, but the (imprecisely estimated) results are larger for siblings spaced further apart akin to what we found for suspensions. In Denmark the results on convictions at age 16 are weaker and

\footnotetext{
${ }^{31}$ We define spacing in months based on date of birth, then convert it to years and round to the nearest integer. For example, if the first-born birth date is November 1994 and the second-born birth date is September 1997 then they are separated by 34 months or 2.8 years, and we assign them spacing of 3 years. Our results are invariant to various ways of measuring spacing.
} 
we do not have precise estimates, yet the effect for both types of prison sentences by age 16 is nearly 40 percent higher for families where the siblings are closely spaced. Our results are more precise at age 21 where we see both higher convictions and incarceration sentencing for the second-borns born up to two years after their older sibling.

The results for Denmark are broadly consistent with the idea that resources and parental attention are diluted more in families where the children are born closer to one another. If boys require more attention from parents (Bertrand and Pan 2013; Autor et al. 2016) then this finding could help to explain why more closely-spaced sibling pairs have greater incidence of delinquency. It's not entirely clear why the birth order effect is greater in Denmark for more closely spaced siblings while the opposite is true for Florida. One possibility could involve different practices regarding maternity leave following pregnancy. As we observed in Section 5.3, a potential mechanism for birth order effects, at least in Denmark, where we observe maternal labor market outcomes, is that the firstborn child experiences extra maternal attention when very young and again when the second-born child is born; if maternal attention is differentially important during very early childhood, then this difference could generate the finding that the birth order effect is particularly pronounced in Denmark when children are closely spaced. In Florida, maternity leave policies are not as generous, so one might imagine that the "double-dose" of extra maternal attention would be attenuated, thereby putting more weight on the time at home without siblings explanation, which privileges first-born children the longer the birth spacing. These explanations, of course, are speculative.

Our identification for the second-born boy effect comes from the comparison of birth order in boy-boy and girl-boy pairs. If there is gender antagonism between siblings then it is plausible that the second-born effects would be larger among the girl-boy families. On the other hand, if there is gender complementarity in delinquency behavior (e.g., it is higher among individuals of the same sex due to peer pressure) we might expect to observe higher estimates among the boy-boy pairs. We present these results in Table A3, and they show mixed evidence. In the case of both types of incarceration sentences in Denmark boys fare modestly worse in families with an older sister as compared with a brother. For example, in the case of incarceration by age 21, second-born boys in girl-boy families have an expected rate 4.3 percentage-points higher than their first-born sister, for an expected rate of 4.4 percent; that rate is 3.3 percent for second-borns in boy-boy families. On the other hand, the results are very similar in the two family compositions for convictions in Denmark and truancy in Florida, while the pattern is actually reversed for juvenile incarceration in Florida. The estimates for the boy-boy comparison are somewhat more modest compared to our main results in Table 2.

So far we have provided suggestive evidence that the negative effects of being a second-born boy are larger for families that need to share the resources between siblings for a longer period of their childhood (spacing) and where the children might require higher levels of management and oversight (opposite-gender, potentially). If these hypotheses about resources in the form of either financial capacity or attention are correct, then it makes sense to investigate heterogeneity by socio-economic status. 
In Table 8 we divide families into those with mothers having less than 12 years of formal education (equivalent of high school dropout in the United States) and those who have 12 or more years of schooling. More educated families tend to have more resources, live in more affluent and safer neighborhoods, and are able to send their children to higher-rated schools. It is also the case that delinquency rates are more than twice as high in the less educated sample for virtually all our measures. That said, the estimates for Denmark suggest very similar second-born effects for convictions among both high and low educated parents. The estimates are larger among the families where mother has less education, but this is offset by the higher baseline delinquency rate among children raised in these households. This pattern is somewhat different for crimes that involve either form of prison sentence. Specifically, by age 16 the differences in rates are much larger among households with lower educated mothers while this pattern is reversed by age 21. In Florida, the estimated effect sizes are similar for both suspensions and truancy, albeit much larger for the former delinquency measure.

A similar resource availability story can be examined by looking at maternal employment but here the expected sign of the effect is not so clear. On the one hand, employed mothers provide additional income and resources, but on the other hand this advantage means that children are send to day care or overseen by unrelated adults. If quality of maternal time outweighs the benefits of what can be purchased with additional income then we could actually see second-born boys doing worse in families where the mother works, especially during early childhood (Fan et al. 2015). Our results, reported in appendix Table A4, document that delinquency is on average higher in households where mom is not employed one year after birth in case of both children. The point estimates and effect-sizes are also higher for the non-employed samples with the exception of convictions by the age of 21 where after scaling they are comparable. Thus, especially for the teenage crime it appears that income effect may dominate maternal time effect for these more extreme outcomes.

There exists ample evidence that children with immigrant backgrounds fare worse in terms of many later life outcomes (Borjas 2006; Abramitzky and Boustan 2016) although the differences vary for schooling outcomes, with Aslund et al. (2011) documenting relative disadvantage in Sweden while Figlio and Ozek (2016) showing superior educational outcomes for the children of immigrants in the United States. Very little is known about the birth order effects in these families. We document the gradient between second-born boys and their older siblings for immigrant and native families in Table 9. First, it is worth noting that the children of immigrants in Denmark have higher convictions and prison sentencing rates, but the children of immigrants in Florida have lower rates of suspensions and absences in comparison to the children of native-born people. In both locations, however, we find larger second-born effect sizes among the children of immigrants relative to the children of native-born residents with a notable exception of teen incarceration in Denmark where the pattern is reversed.

Although Denmark is fairly racially and ethnically homogeneous, in Florida the student population we investigate is 20 percent African American and another 18 percent Hispanic. It is also the case that African Americans and Hispanics have on average lower socio-economic status and their 
children fare worse in schooling outcomes. Thus, we present results separately for African Americans, non-African Americans, Hispanics and non-Hispanics in Table 10. Absenteeism is lower among these two minority groups in comparison to the rest of the population, but the suspension rate for African Americans is more than twice as high as for non-African Americans. The second-born effect is similar among Hispanics and non-Hispanics for suspensions but larger for the former group for truancy. When comparing African Americans to non-African Americans, however, the effect sizes for both outcomes are larger among non-African Americans.

Thus far we have focused in our analysis on a more positively selected sample of stable families where the mother and father are the same for both children. However a non-negligible fraction of children is raised in non-intact families where parents differ across births. In Florida 30 percent of children in families with two or more children have different or unknown fathers for the first two births, while in Denmark this number is lower (9.5 percent) but still non-trivial. Since family instability is likely correlated with behavioral problems, and thus delinquency (Autor et al. 2016), we did not want to pool together these two types of families. In Table A5 we present separately the results for boy-boy and girl-boy families with different fathers across the two births. ${ }^{32}$ First, with the exception of truancy, the delinquency rates are much higher in these families in comparison to the baseline sample - from about two times for convictions and suspensions to five times for teenage incarceration. For convictions and suspensions, we find very similar effect sizes as in Table 2. In cases where the mean values increase the most across samples, suspended or implemented imprisonment sentences, we do not estimate any significant birth order gaps. The point estimates are also substantially smaller than these documented for more stable families. A hypothesis consistent with this set of results may suggest that resources and parental attention that could prevent the most extreme behavior do not matter so much in families with changing male role models. It is also possible that changing family structure might alter the ways in which male role models treat first-born versus second-born children.

\subsection{Robustness checks}

Given the very large magnitude of these differences between first- and second-born children, we check the robustness of the results in a number of ways. In the main set of results our fixed effects specification controls only for cohort effects but it is possible that our estimates are still biased because we do not account for mother time varying characteristics like marital status and education or place of residence. These characteristics could change across births and influence the secondborn either positively (e.g. mother improving her education) or negatively (e.g. family moving to a poorer neighborhood due to reduced resources). When we control for maternal age at birth, maternal education, maternal marital status and location at the time of birth in the fixed effects models our estimates are similar (panel A in Table A6).

In Table 5 we have documented that second-borns are moderately healthier at the time of birth

\footnotetext{
${ }^{32}$ The set of families where the identity of the father is unknown for at least one birth is 20.6 percent in Florida and only 2.3 percent in Denmark.
} 
in comparison to their older siblings, and thus, if there is a causal effect of health at birth on delinquency then the main results could be mediated through improved health. When we control for birth outcomes in our preferred specification in panel B of Table A6, however, the results do not change which suggests that better health in infancy does not moderate the effects on delinquency. At the same time, because health at birth has a causal effect on cognitive development (Figlio et al. 2014) our second-born estimates for test scores increase marginally in magnitude when we control for birth weight.

One explanation for our main results pertains to potential stopping rules that parents use when determining family size. In our preferred sample we focus on the first two births among families with two or more children, but it is possible that issues associated with the second-born child might induce some families to cease their fertility following the second-born child. To address this issue, we drop from the sample all families for whom we observe exactly two children (panel $\mathrm{C}$ in Table A6). This cuts our sample by about 60 and 85 percent in Denmark and Florida, respectively. In Denmark this is almost entirely due to families stopping their fertility at parity two, while in Florida we lose even more observations because of the nature of the data - since we only observe births over 9 years, it is possible that the families which we drop now as having exactly two children will continue their fertility beyond the year where we can observe them. First, it is worth noting that in these larger families the average delinquency rates for the first-born boys are higher than in the

preferred sample which could be related to the lower socioeconomic status of families with higher fertility. Nonetheless, our results are very stable whether we include exact parity two families or not.

\subsection{Effects for girls}

Boys and girls have much different delinquency rates, they go through puberty at different ages, and they perform better in certain subjects. Therefore, in order to facilitate an "apples to apples" comparison in our estimation strategy we have thus far focused on the comparison of second-born boys to their older siblings - whether both brothers and sisters in the main sample or only older brothers in panel A of appendix Table A3. But the birth order gradient in delinquency for girls is also of interest, and we therefore present the estimates for the sample of girl-girl and boy-girl comparisons in panels $\mathrm{C}$ and $\mathrm{D}$ of appendix Table A3.

There is much less variation in delinquent behavior of girls relative to boys, with means for first-born girl in girl-girl families being between 54 to nearly 100 percent lower than means for first-born boys in boy-boy families. The notable exception here is truancy, which is similar across genders. Consequently, the majority of coefficients for Denmark lack precision - in Panel C of Table A3 - with only suspended sentences pointing towards 84 percent disadvantage of second-born girl in comparison to her older sister. For Florida we estimate a statistically significant 43 percent gap between sisters in suspensions and a much smaller 2.8 percent gap in truancy. The difference in suspensions is about twice the size compared to the boy-boy difference, while the truancy difference is comparable across these family types. We document the persistence of these differences in Florida 
in Figure A2. In general, the negative coefficients for Denmark depicted in Figure A1, suggesting advantage of second-born girls, appear to be driven by the opposite-gender contrast. Indeed, all estimates in Panel D of Table A3 suggest that the second-born girl disadvantage is slightly smaller when they have older brother which is in contrast to what we discussed when comparing Panels A and $\mathrm{B}$ for boys. ${ }^{33}$ Overall, we view these results for girls as consistent with our findings for boys, with second-born girls being more disadvantaged in comparison to their sisters at least in terms of less severe school delinquency outcomes.

We also investigate the degree to which any differences in birth order effects by second-born gender are possibly due to different mechanisms affecting girls versus boys. For instance, it may be the case that second-born girls are in better health, or that parents invest more in early human capital if the second-born child is female. As can be seen in appendix Table A7, compared to the parallel second-born boy mechanisms presented in Table 5 , most of the potential mechanisms that we explored (e.g., neonatal health, pre-kindergarten participation, and school quality) are remarkably similar between second-born boys and second-born girls. The same conclusion applies to maternal labor market activity after birth depicted in Figures 4 and A4. This general pattern of findings leads us to believe that the mechanisms we explored do not account for a substantial part of boy-girl differences in birth order effects on delinquency.

\section{Conclusions}

Previous research has paid considerable attention to identifying the effects of birth order on a range of cognitive outcomes such as test scores, educational attainment, and wages. We contribute to this literature by studying a set of more extreme outcomes relating to delinquency. In order to gauge the degree to which birth order is determining delinquent behavior, we perform, to the extent practicable, parallel analyses in two rich but otherwise considerably different societies - Denmark and the United States (Florida). These societies have much different approaches to crime and punishment and are demographically very different, but our sets of findings are fundamentally quite similar.

We find, consistently across both locations, that second-born boys are substantially more likely to exhibit delinquency problems compared to their older sibling. Second-born boys in Denmark have substantially higher rates of juvenile crime, particularly severe violent crime, and imprisonment than do their older siblings. We observe antecedents for these patterns in terms of early delinquency problems (especially disciplinary behavior that results in suspensions but also in middle school truancy) as well as in terms of direct measures of conduct problems and hyperactivity at age 12 . The gaps in delinquency are smaller when we investigate the effect of being a second-born girl.

We explore a wide variety of early-life outcomes in order to understand the mechanisms through which birth order effects are occurring. We are able to rule out broad classes of explanations. We

\footnotetext{
${ }^{33}$ We find similar effects for second-born girls to those for second-born boys in terms of reading, and for second-born girls the estimates for math are u-shaped. We present these results in Figure A3. In Figure A5 we further present evidence on quality of schools attended by second-born girls in these girl-girl and boy-girl families. Akin to estimates for second-born boys we find elevated probability of attending better quality school in first grade that then diminishes and oscillates around zero.
} 
find no evidence that second-born children are less healthy, and indeed second-born children appear to be healthier at birth and have lower rates of disability in childhood. We also find no evidence that parents invest less in second-born children's education. These children attend no-worse schools and are more likely to attend pre-kindergarten. We consider differences in parental attention as a potential contributing factor to the gaps in delinquency across the birth order. Second-born children tend to have less maternal attention than do their older siblings because first-born children experience their mother's maternity leaves and temporarily reduced labor market participation both following their own births as well as following the birth of the second-born. Therefore, in addition to the fact that first-borns experience undivided attention until the arrival of the second-born, we discovered that the arrival of the second-born child has the potential to extend the early-childhood parental investment in the first-born child.

These new results have important implications for social policy. Crime, delinquency, and incarceration have enormous social costs and are associated with major losses in human potential. Our findings that birth order appears to influence the likelihood of delinquency among boys, and that differences begin to appear early, suggests potentially fruitful avenues for monitoring and interventions. Our findings regarding systematically different dosages of early-childhood parental attention as a plausible mechanism also engender further discussion of parental leave as a long-run social benefit. 


\section{References}

Abramitzky, Ran and Leah Boustan, "Immigration in American Economic History," Journal of Economic Literature, 2016, forthcoming.

Adler, Alfred, "Characteristics of the first, second, and third child," Children, 1928, 3 (5), 14.

Andersen, Simon, Louise Beuchert-Pedersen, Skyt Helena Nielsen, and Mette Thomsen, "2L Rapport: Undersogelse af effekten af tolaererordninger," 2014.

Angrist, Joshua D, Victor Lavy, and Analia Schlosser, "Multiple Experiments for the Causal Link between the Quantity and Quality of Children," Journal of Labor Economics, 2010.

Argys, Laura, Susan Averett, and Daniel Rees, "The Effect of Older Siblings on Adolescent Behavior: Is it Siblings or Parents," 2006.

Aslund, Olof, Per-Anders Edin, Peter Fredriksson, and Hans Gronqvist, "Peers, Neighborhoods, and Immigrant Student Achievement: Evidence from a Placement Policy," American Economic Journal: Applied Economics, 2011.

Autor, David, David Figlio, Krzysztof Karbownik, Jeffrey Roth, and Melanie Wasserman, "Family Disadvantage and the Gender Gap in Behavioral and Educational Outcomes," 2016.

Averett, Susan, Laura Argys, and Daniel Rees, "Older Siblings and Adolescent Risky Behavior: Does Parenting Play a Role?," Journal of Population Economics, 2011, 24 (3), 957-978.

Bagger, Jesper, Javier Birchenall, Hani Mansour, and Sergio Urzua, "Education, Birth Order, and Family Size," 2013.

Becker, Gary S., "An Economic Analysis of Fertility," in "Demographic and Economic Change in Developed Countries," Columbia University Press, 1960, pp. 209-240.

- and Gregg H. Lewis, "On the Interaction between the Quantity and Quality of Children," Journal of Political Economy, 1973, 81 (2), S279-S288.

- and Nigel Tomes, "Child Endowments and the Quantity and Quality of Children," Journal of Political Economy, 1976, 84 (4), S143-S162.

Behrman, Jere R. and Paul Taubman, "Birth Order, Schooling, and Earnings," Journal of Labor Economics, 1986, 4 (3), 121-145.

Berger, Eva M. and Katharina C. Spiess, "Maternal Life Satisfaction and Child Outcomes: Are They Related?," Journal of Economic Psychology, 2011, 32 (1), 142-158.

Bertrand, Marianne and Jessica Pan, "The Trouble with Boys: Social Influence and the Gender Gap in Disruptive Behavior," American Economic Journal: Applied Economics, 2013, 5 (1), 32-64. 
Black, Sandra, Erik Gronqvist, and Bjorn Ockert, "Born to Lead? The Effect of Birth Order on Non-Cognitive Skills," 2015.

_, Paul Devereux, and Kjell Salvanes, "The More The Merrier? The Effects of Family Size and Birth Order on Children's Education," Quarterly Journal of Economics, 2005, pp. 669-700.

_ , _ and _ , "Too Young to Leave the Nest? The Effects of School Starting Age," Review of Economics and Statistics, 2011, 93 (2), 455-467.

_ , Sanni Breining, David Figlio, Jonathan Guryan, Krzysztof Karbownik, Skyt Helena Nielsen, Jeffrey Roth, and Marianne Simonsen, "Sibling Spillovers," 2016.

Borjas, George, "Making it in America: Social Mobility in the Immigrant Population," Future of Children, 2006, 16 (2), 55-71.

Buckles, Kasey and Elizabeth Munnich, "Birth Spacing and Sibling Outcomes," Journal of Human Resources, 2012, 47 (3), 613-642.

Butcher, Kristin F. and Anne Case, "The Effect of Sibling Sex Composition on Women's Education and Earnings," Quarterly Journal of Economics, 1994, 109 (3), 531-563.

Carrell, Scott E. and Mark Hoekstra, "Externalities in the Classroom: How Children Exposed to Domestic Violence Affect Everyone's Kids," American Economic Journal: Applied Economics, 2010, 2 (1), 211-228.

_ , _ , and Elira Kuka, "The Long-Run Effects of Disruptive Peers," 2016.

Chen, Yen-Chien, Stacey H. Chen, and Jin-Tau Liu, "Separate Effects of Sibling Gender and Family Size on Educational Achievements - Methods and First Evidence from Population Birth Registry," 2009.

Conley, Dalton, "Sibship Sex Composition: Effects on Educational Attainment," Social Science Research, 2000, 29 (3), 441-457.

- and Rebecca Glauber, "Parental Educational Investment and Children's Academic Risk: Estimates of the Impact of Sibship Size and Birth Order from Exogenous Variation in Fertility," Journal of Human Resources, 2006, 41, 722-737.

Conti, Gabriella, James J Heckman, and Rodrigo Pinto, "The Effects of Two Influential Early Childhood Interventions on Health and Healthy Behaviors," Economic Journal, 2016, 126 (596), F28-F65.

Cundiff, Patrick, "Ordered Delinquency: The "Effects" of Birth Order on Delinquency," Personality and Social Psychology Bulletin, 2013, 39 (8), 1017-1029.

Cunha, Flavio, James J Heckman, and Schennach Susanne M., "Estimating the Technology of Cognitive and Noncognitive Skill Formation," Econometrica, 2010, 78 (3), 883-931. 
Currie, Janet and Wanchuan Lin, "Chipping away at health: More on the relationship between income and child health," Health Affairs, 2007, 26, 331-344.

Dayioglu, Meltem, Murat G. Kirdar, and Aysit Tansel, "Impact of Sibship Size, Birth Order and Sex Composition on School Enrolment in Urban Turkey," Oxford Bulletin of Economics and Statistics, 2009, 71 (3), 399-426.

de Haan, Monique, "Birth order, family size and educational attainment," Economics of Education Review, 2010, 29, 576-588.

Deschenes, Olivier, "Estimating the Effects of Family Background on the Return to Schooling," 2002.

Ejrnæs, Mette and Claus C. Portner, "Birth Order and the Intrahousehold Allocation of Time and Education," Review of Economics and Statistics, 2004, 86 (4), 1008-1019.

Fan, Xiaodong, Hanming Fang, and Simen Markussen, "Mother's Employment and Children's Educational Gender Gap," 2015.

Figlio, David and Umut Ozek, "Cross-Generational Differences in Educational Outcomes in the Second Great Wave of Immigration," 2016.

_, Jonathan Guryan, Krzysztof Karbownik, and Jeffrey Roth, "The Effects of Poor Neonatal Health on Children's Cognitive Development," 2013.

_ , _ , , and _ , "The Effects of Poor Neonatal Health on Children's Cognitive Development," American Economic Review, 2014, 104 (12), 3921-55.

Galor, Oded and David N. Weil, "Population, Technology, and Growth: From Malthusian Stagnation to the Demographic Transition and Beyond," American Economic Review, 2000, 90 (4), 806-828.

Goodman, Anna, Richard Rowe, and Ye Gan, "http://www.sdqinfo.com/c3.html," 2010.

Goodman, Robert, "The Strengths and Difficulties Questionnaire: A Research Note," Journal of Child Psychology and Psychiatry, 1997, 38, 581-586.

Gupta, Nabanita Datta and Marianne Simonsen, "Effects of Universal Child Care Participation on Pre-teen Skills and Risky Behaviors," 2010.

Härkönen, Juho, "Birth Order Effects on Educational Attainment and Educational Transitions in West Germany," European Sociological Review, 2014, 30 (2), 166-179.

Hauser, Robert M. and Hsiang-Hui D. Kuo, "Does the Gender Composition of Sibships Affect Women's Educational Attainment?," Journal of Human Resources, 1998, 33 (3), 644-657. 
Havnes, Tarjei and Magne Mogstad, "No Child Left Behind: Subsidized Child Care and Children's Long-Run Outcomes," American Economic Journal: Economic Policy, 2011, 3 (2), 97-129.

Heckman, James J, "Policies to foster human capital," Research in Economics, 2000, 54, 3-56.

Heller, Sara B., Anuj K. Shah, Jonathan Guryan, Jens Ludwig, Sendhil Mullainathan, and Harold A. Pollack, "Thinking Fast and Slow? Some Field Experiments to Reduce Crime and Dropout in Chicago," 2015.

Hotz, Joseph V. and Juan Pantano, "Strategic Parenting, Birth Order and School Performance," Journal of Population Economics, 2015.

Joensen, Juanna and Skyt Helena Nielsen, "Spillovers in Educational Choice," 2015.

Kaestner, Robert, "Are Brothers Really Better? Sibling Sex Composition and Educational Achievement Revisited," Journal of Human Resources, 1997, 32 (2), 250-284.

Kaufmann, Katja and Matthias Messner, "Child Development and the Timing and Causes of Birth-Order Effects," 2015.

Kelly, Yvonne, Amanda Sacker, Ron Gray, Jon Kelly, Dieter Wolke, and Maria A. Quigley, "Light drinking in pregnancy, a risk for behavioural problems and cognitive deficits at 3 years of age?," International Journal of Epidemiology, 2009, 38, 129-140.

Kristoffersen, Jannie, Morten Kraegpoth, Skyt Helena Nielsen, and Marianne Simonsen, "Disruptive School Peers and Student Outcomes," 2014.

Lehmann, Jee-Yeon K., Ana Nuevo-Chiquero, and Marian Vidal-Fernandez, "The early origins of birth order differences in children's outcomes and parental behavior," 2014.

Lundberg, Evelina and Helena Svaleryd, "Birth Order and Child Health," 2016.

Manski, Charles F., "Identification problems in social sciences," 1995.

Mogstad, Magne and Matthew Wiswall, "Testing the Quantity-Quality Model of Fertility: Linearity, Marginal Effects, and Total Effects," Quantitative Economics, 2016.

Nagin, Daniel, "Deterrence: A Review of the Evidence by a Criminologist for Economists," Annual Review of Economics, 2013, 5, 83-105.

Price, Joseph, "Parent-Child Quality Time: Does Birth Order Matter?," Journal of Human Resources, 2008, 43 (1), 240-265.

Rouse, Cecilia, David Figlio, Dan Goldhaber, and Jane Hannaway, "Feeling the Florida Heat? How Low-Performing Schools Respond to Voucher and Accountability Pressure," American Economic Journal: Economic Policy, 2013, 5 (2), 251-281. 
Silles, Mary, "The Implications of Family Size and Birth Order for Test Scores and Behavioral Development," Economics of Education Review, 2010, 29 (5), 795-803.

Smith, Thomas E., "Academic Achievement and Teaching Younger Siblings," Social Psychology Quarterly, 1993, 56 (1), 77-85.

Statistik, Danmarks, "Fodselsargange efter kon, alder ved forste dom og lovovertraedelse."

Sulloway, Frank, Born to Rebel: Birth Order, Family Dynamics, and Creative Lives, New York: Pantheon, 1996.

Widom, C. S., "The cycle of violence," Science, 1989, 244 (4901), 160-166.

Zajonc, Robert B. and Gregory B. Markus, "Birth order and intellectual development," Psychological Review, 1975, 82 (1), 74-88. 


\section{Figures and Tables}

Table 1: Descriptive Statistics

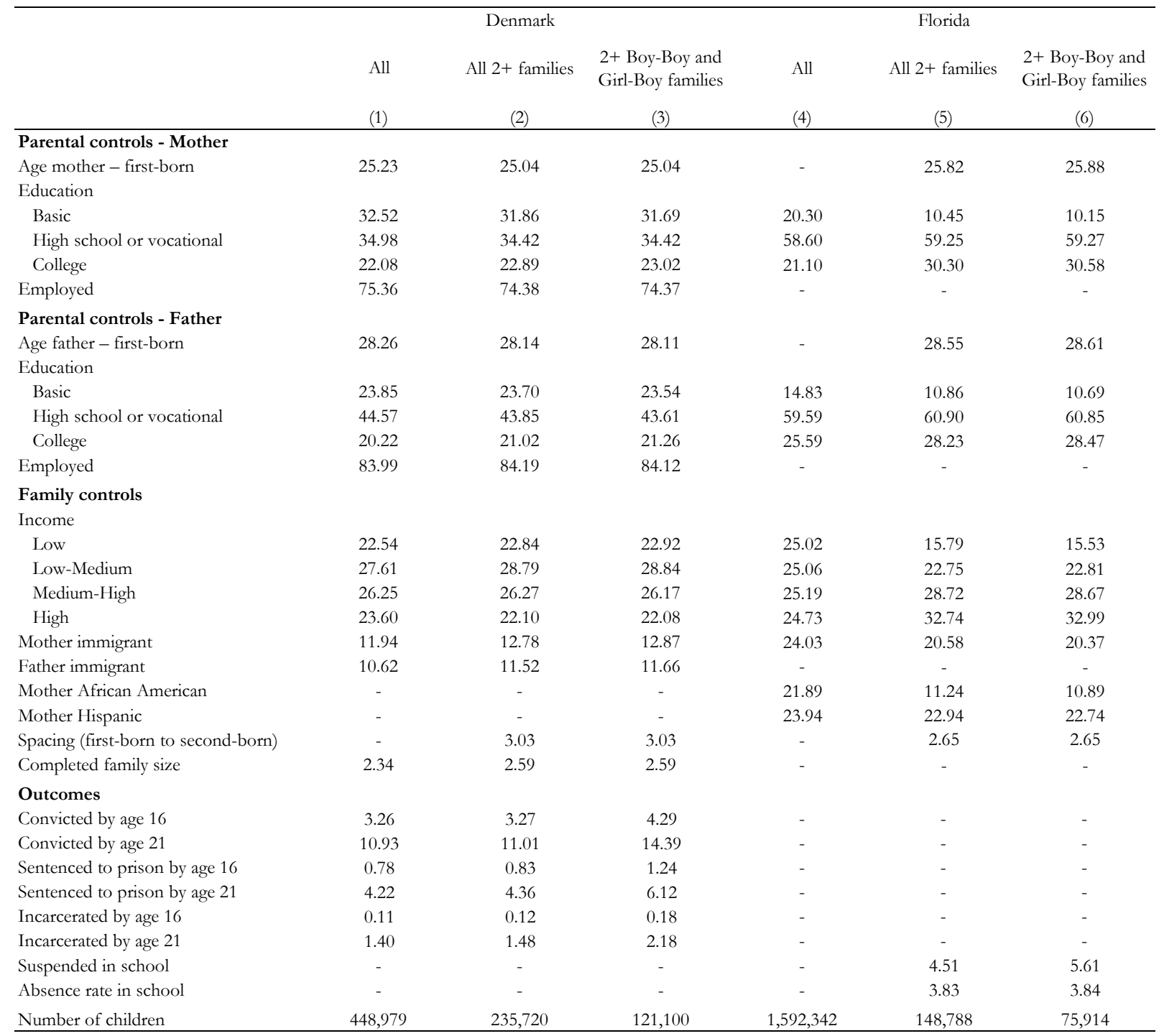

Note: Sample in column (1) is based on all singleton births between 1981 and 1990 in Denmark. Sample in column (4) is based on all singleton births between 1994 and 2002 in the state of Florida. We are unable to provide maternal age at first birth for this sample since we do not know older and younger siblings for the full population of births. We also do not observe education for fathers who do not appear on the birth certificate and the sample size for paternal education is $1,277,106$. Columns (2) and (5) are based on the sample of families with two or more children and the same father. We can link siblings only in about 70 percent of counties of Florida and only if both births occurred in the state of Florida between 1994 and 2002. We can link all siblings in Denmark. Columns (3) and (6) present the subsample of interest with second-born boys. Employment and income in Denmark are measured in the year before birth. All other controls are measured at the time of child's birth. Individual level income in Denmark and ZIP code of birth median income based on 2000 Census for Florida. Spacing refers to distance in years between first and second birth. Binary variables are multiplied by 100 giving percent values. 
Table 2: Main results

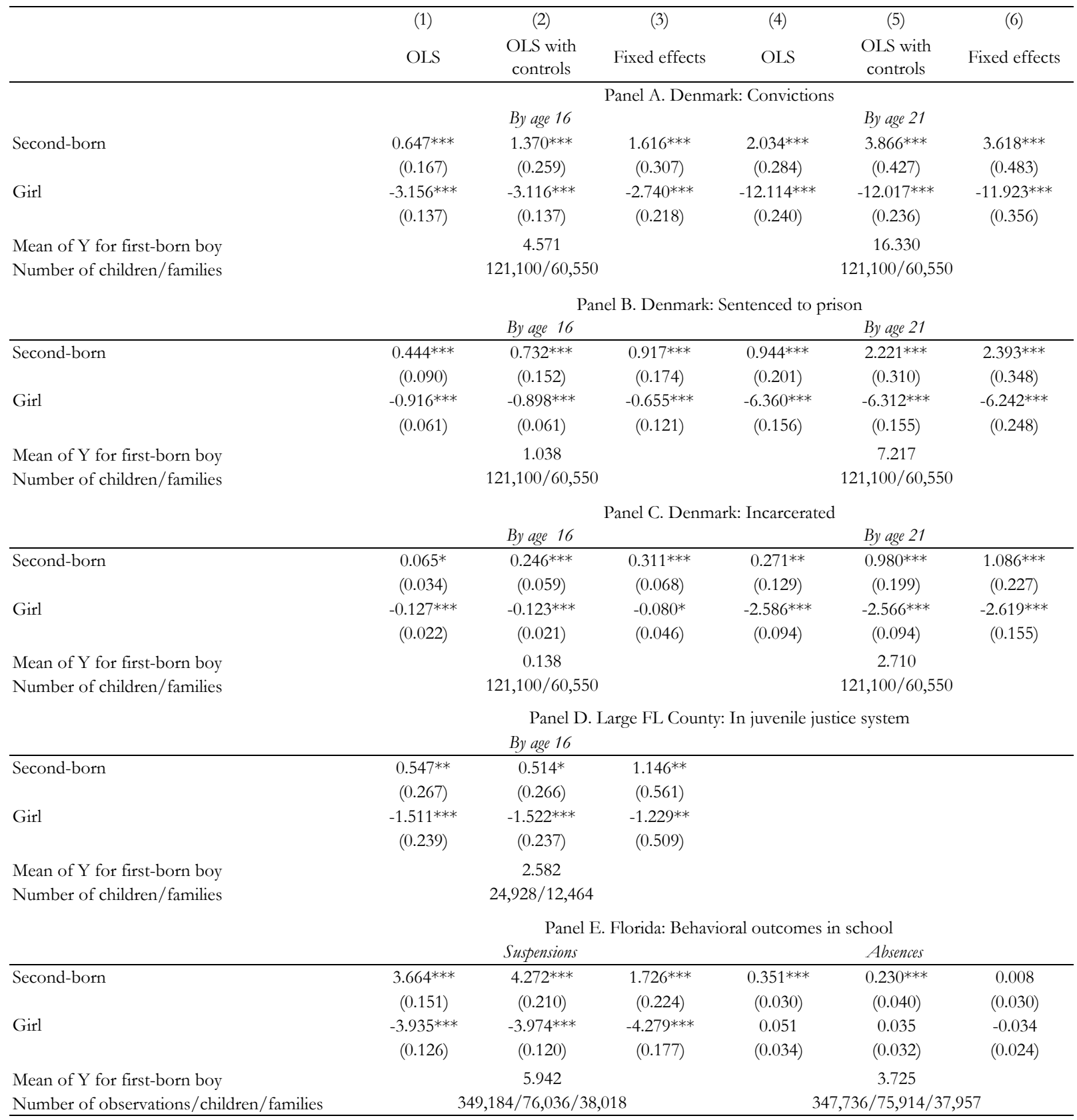

Note: Standard errors clustered at mother level. All dependent variables, except for absence rate, are binary indicators multiplied by 100. These are: probability of being convicted (panel A), probability of being sentenced to suspended imprisonment (panel B), probability of being incarcerated (panel C), probability of being in juvenile detention center (panel D) and probability of being suspended in school (columns (1) to (3) in panel E). OLS and FE regressions in columns (1), (3), (4) and (6) include only child birth year dummies. Controls in columns (2) and (5) in Panels A, B and $\mathrm{C}$ in addition to birth year dummies include mother's age at first birth, mother's age, father's age, municipality dummies, maternal and paternal education, maternal and paternal employment, family income, immigrant dummy, number of children in family. Controls in column (2) in Panel D in addition to birth year dummies include first observed limited English proficiency, subsidized school meal status, and average school meal status in student microneighborhood. Controls in columns (2) and (5) in Panel E in addition to birth year dummies include mother age at first birth, mother age, father age, ZIP code of birth dummies, mother and father education dummies as well as indicator variables for race, ethnicity, immigrant status and marital status at the time of birth. Panels A, B and C are based on 1981 to 1990 birth cohorts; panel D is based on September 1979 to August 1989 births while panel D is based on 1994 to 2002 birth cohorts. 
Table 3: Types of crime by age 21: Denmark birth cohorts 1981-1990

\begin{tabular}{lccc}
\hline & $(1)$ & $(2)$ & $(3)$ \\
& Violent Crime & Property Crime & Special Crime \\
\hline Second-born & $1.606^{* * *}$ & $2.163^{* * *}$ & $2.099^{* * *}$ \\
& $(0.292)$ & $(0.416)$ & $(0.356)$ \\
Girl & $-3.925^{* * *}$ & $-7.406^{* * *}$ & $-5.877^{* * *}$ \\
& $(0.204)$ & $(0.300)$ & $(0.257)$ \\
Mean of Y for first-born boy & 4.526 & 10.885 & 6.551 \\
Number of children/families & & $121,100 / 60,550$ & \\
\hline
\end{tabular}

Note: Standard errors clustered at mother level. All estimates come from fixed effects regressions controlling for child birth year dummies. All crime outcomes are measured based on convictions for violent, property and special offenses. Special crime includes for example drug offenses and illegal weapon possession.

Table 4: Short-run non-cognitive outcomes: Denmark birth cohorts 1999-2000

\begin{tabular}{lcccc}
\hline & $(1)$ & $(2)$ & $(3)$ & $(4)$ \\
& Close to average & Slightly raised & High & Very high \\
\hline \multirow{2}{*}{ Second-born } & $-0.041^{*}$ & Panel A: Total difficulties score & \\
& $(0.023)$ & $(0.018)$ & $(0.011)$ & $(0.013)$ \\
Girl & 0.009 & $-0.033^{* *}$ & 0.009 & 0.015 \\
& $(0.019)$ & $(0.014)$ & $(0.010)$ & $(0.011)$ \\
Mean of Y for first-born boy & 0.829 & 0.094 & 0.034 & 0.043 \\
& & Panel B: Prosociality score & \\
Second-born & -0.024 & 0.020 & 0.002 & 0.003 \\
Girl & $(0.027)$ & $(0.021)$ & $(0.017)$ & $(0.014)$ \\
& $0.138^{* * *}$ & $-0.062^{* * *}$ & $-0.041 * * *$ & $-0.035^{* * *}$ \\
Mean of Y for first-born boy & $(0.021)$ & $(0.017)$ & $(0.013)$ & $(0.010)$ \\
Number of children & 0.695 & 0.155 & 0.090 & 0.059 \\
\hline
\end{tabular}

Note: Standard errors clustered at mother level. All outcome variables are binary indicators. OLS regressions in columns (1)-(4) include the following controls: child birth year dummies, mother age at first birth, mother age, father age, municipality dummies, maternal and paternal education, maternal and paternal employment, family income, immigrant dummy, number of children in family. The questionnaire was answered by 6th grade students from birth cohorts 1998-2000. Panel A is a combination of emotional problems score, conduct problems score, hyperactivity score and peer effects problems score. We present the results for these scores separately in Table A7. 


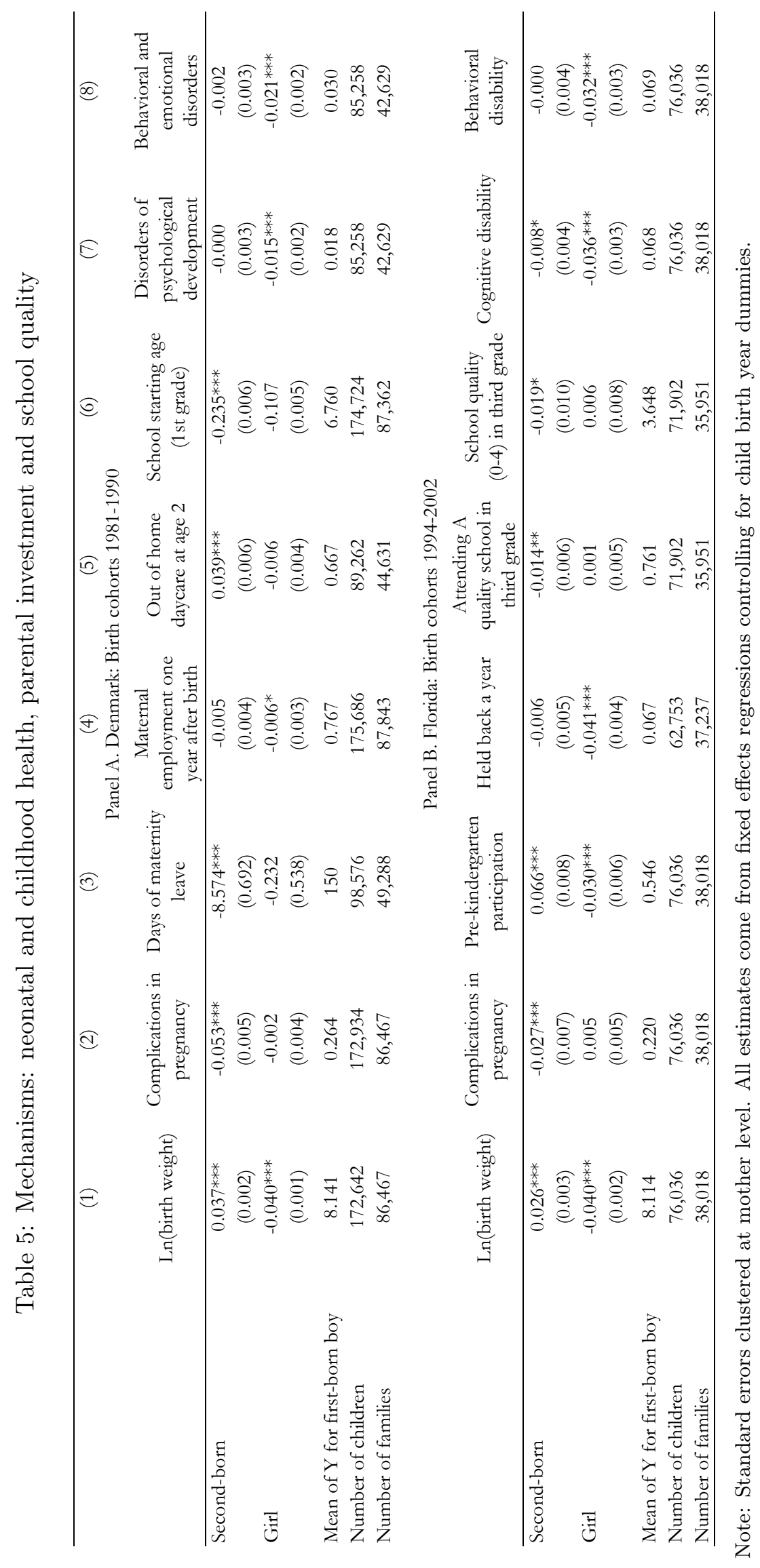


Table 6: Short-run cognitive outcomes

\begin{tabular}{|c|c|c|c|c|}
\hline & $(1)$ & $(2)$ & (3) & (4) \\
\hline & \multicolumn{2}{|c|}{ Denmark: Birth cohorts 1986-1997 } & \multicolumn{2}{|c|}{ Florida: Birth cohorts 1994-2002 } \\
\hline & Math & Reading & Math & Reading \\
\hline \multirow[t]{2}{*}{ Second-born } & $-0.109 * * *$ & $-0.137 * * *$ & 0.013 & $-0.076^{* * *}$ \\
\hline & $(0.010)$ & $(0.012)$ & $(0.011)$ & $(0.011)$ \\
\hline \multirow[t]{2}{*}{ Girl } & $-0.084 * * *$ & $0.347 * * *$ & $-0.039 * * *$ & $0.081 * * *$ \\
\hline & $(0.007)$ & $(0.009)$ & $(0.009)$ & $(0.009)$ \\
\hline Mean of Y for first-born boy & 0.278 & -0.044 & 0.459 & 0.386 \\
\hline Number of observations & 144,906 & 144,906 & 307,402 & 310,650 \\
\hline Number of children & 144,906 & 144,906 & 72,888 & 72,998 \\
\hline Number of families & 72,453 & 72,453 & 36,444 & 36,499 \\
\hline
\end{tabular}

Note: Standard errors clustered at mother level. All estimates come from fixed effects regressions controlling for child birth year dummies. 
Table 7: Heterogeneity effects by spacing between first- and second-born child

\begin{tabular}{|c|c|c|c|c|}
\hline & (1) & (2) & (3) & (4) \\
\hline & $\begin{array}{c}\text { Spaced } 1-2 \text { years } \\
\text { apart }\end{array}$ & $\begin{array}{c}\text { Spaced } 3+\text { years } \\
\text { apart }\end{array}$ & $\begin{array}{c}\text { Spaced } 1-2 \text { years } \\
\text { apart }\end{array}$ & $\begin{array}{c}\text { Spaced } 3+\text { years } \\
\text { apart }\end{array}$ \\
\hline & \multicolumn{4}{|c|}{ Panel A. Denmark: Convictions } \\
\hline & \multicolumn{2}{|c|}{ By age 16} & \multicolumn{2}{|c|}{ By age 21} \\
\hline \multirow[t]{2}{*}{ Second-born } & 0.143 & 0.332 & $4.119^{* * *}$ & $1.982 * *$ \\
\hline & $(0.704)$ & $(0.487)$ & $(1.073)$ & $(0.796)$ \\
\hline \multirow[t]{2}{*}{ Girl } & $-2.926 * * *$ & $-2.625^{* * *}$ & $-13.194 * * *$ & $-11.081^{* * *}$ \\
\hline & $(0.365)$ & $(0.270)$ & $(0.577)$ & $(0.450)$ \\
\hline Mean of Y for first-born boy & 5.213 & 4.137 & 18.112 & 15.127 \\
\hline Number of children & 48,552 & 72,548 & 48,552 & 72,548 \\
\hline \multirow[t]{3}{*}{ Number of families } & 24,276 & 36,274 & 24,276 & 36,274 \\
\hline & \multicolumn{4}{|c|}{ Panel B. Denmark: Sentenced to prison } \\
\hline & \multicolumn{2}{|c|}{ By age 16} & \multicolumn{2}{|c|}{ By age 21} \\
\hline Second-born & $0.884^{* *}$ & 0.203 & $4.198^{* * *}$ & $0.935^{*}$ \\
\hline & $(0.412)$ & $(0.263)$ & $(0.813)$ & $(0.546)$ \\
\hline Girl & $-0.863^{* * *}$ & $-0.519^{* * *}$ & $-6.977 * * *$ & $-5.762^{* * *}$ \\
\hline & $(0.208)$ & $(0.146)$ & $(0.417)$ & $(0.307)$ \\
\hline Mean of Y for first-born boy & 1.407 & 0.789 & 8.202 & 6.552 \\
\hline Number of children & 48,552 & 72,548 & 48,552 & 72,548 \\
\hline \multirow[t]{3}{*}{ Number of families } & 24,276 & 36,274 & 24,276 & 36,274 \\
\hline & \multicolumn{4}{|c|}{ Panel C. Denmark: Incarcerated } \\
\hline & \multicolumn{2}{|c|}{ By age 16} & \multicolumn{2}{|c|}{ By age 21} \\
\hline Second-born & $0.435^{* *}$ & $0.115^{*}$ & $1.896^{* * *}$ & 0.108 \\
\hline & $(0.180)$ & $(0.070)$ & $(0.552)$ & $(0.335)$ \\
\hline Girl & $-0.191 * *$ & -0.006 & $-3.080^{* * *}$ & $-2.315^{* * *}$ \\
\hline & $(0.091)$ & $(0.047)$ & $(0.272)$ & $(0.185)$ \\
\hline Mean of Y for first-born boy & 0.230 & 0.075 & 3.203 & 2.377 \\
\hline Number of children & 48,552 & 72,548 & 48,552 & 72,548 \\
\hline \multirow[t]{2}{*}{ Number of families } & 24,276 & 36,274 & 24,276 & 36,274 \\
\hline & \multicolumn{4}{|c|}{$\begin{array}{l}\text { Panel D. Large FL County: In juvenile justice system } \\
\text { By age } 16\end{array}$} \\
\hline \multirow[t]{2}{*}{ Second-born } & 0.449 & 0.911 & & \\
\hline & $(0.886)$ & $(1.516)$ & & \\
\hline \multirow[t]{2}{*}{ Girl } & $-1.377 * *$ & -0.925 & & \\
\hline & $(0.623)$ & $(0.886)$ & & \\
\hline Mean of Y for first-born boy & 2.540 & 2.674 & & \\
\hline Number of children & 16,958 & 7,970 & & \\
\hline \multirow[t]{3}{*}{ Number of families } & 8,479 & 3,985 & & \\
\hline & \multicolumn{4}{|c|}{ Panel E. Florida: Behavioral outcomes in school } \\
\hline & \multicolumn{2}{|c|}{ Suspensions (G1 to G8) } & \multicolumn{2}{|c|}{ Absences (G4 to G8) } \\
\hline \multirow[t]{2}{*}{ Second-born } & $1.748^{* * *}$ & $2.911 * * *$ & $0.144 * *$ & $0.416^{* * *}$ \\
\hline & $(0.426)$ & $(0.433)$ & $(0.071)$ & $(0.096)$ \\
\hline \multirow[t]{2}{*}{ Girl } & $-4.770^{* * *}$ & $-3.620 * * *$ & $-0.144 * * *$ & $-0.088^{*}$ \\
\hline & $(0.249)$ & $(0.246)$ & $(0.042)$ & $(0.050)$ \\
\hline Mean of Y for first-born boy & 6.764 & 4.842 & 3.761 & 3.485 \\
\hline Number of observations & 198,872 & 150,312 & 113,774 & 86,382 \\
\hline Number of children & 40,064 & 35,972 & 35,076 & 31,360 \\
\hline Number of families & 20,032 & 17,986 & 17,538 & 15,680 \\
\hline
\end{tabular}

Note: Standard errors clustered at mother level. All estimates come from fixed effects regressions controlling for child birth year dummies. 
Table 8: Heterogeneity effects by maternal education at birth

\begin{tabular}{|c|c|c|c|c|}
\hline & $\begin{array}{c}(1) \\
<12 \text { years }\end{array}$ & $\begin{array}{c}(2) \\
12+\text { years }\end{array}$ & $\begin{array}{c}(3) \\
<12 \text { years }\end{array}$ & $\begin{array}{c}(4) \\
12+\text { years }\end{array}$ \\
\hline & \multicolumn{4}{|c|}{ Panel A. Denmark: Convictions } \\
\hline & \multicolumn{2}{|c|}{ By age 16} & \multicolumn{2}{|c|}{ By age 21} \\
\hline Second-born & $\begin{array}{c}1.651 * * * \\
(0.629)\end{array}$ & $\begin{array}{l}0.642^{*} \\
(0.339)\end{array}$ & $\begin{array}{c}4.468^{* * *} \\
(0.936)\end{array}$ & $\begin{array}{c}2.301 * * * \\
(0.599)\end{array}$ \\
\hline Girl & $\begin{array}{c}-3.511 \text { *** } \\
(0.451)\end{array}$ & $\begin{array}{c}-1.629 * * * \\
(0.234)\end{array}$ & $\begin{array}{c}-16.208^{* * *} \\
(0.698)\end{array}$ & $\begin{array}{c}-8.580 * * * \\
(0.425)\end{array}$ \\
\hline Mean of Y for first-born boy & 6.559 & 2.741 & 22.594 & 11.158 \\
\hline Number of children & 39,386 & 68,234 & 39,386 & 68,234 \\
\hline \multirow[t]{3}{*}{ Number of families } & 19,693 & 34,117 & 19,693 & 34,117 \\
\hline & \multicolumn{4}{|c|}{ Panel B. Denmark: Sentenced to prison } \\
\hline & \multicolumn{2}{|c|}{ By age 16} & \multicolumn{2}{|c|}{ By age 21} \\
\hline Second-born & $\begin{array}{c}1.259 * * * \\
(0.365)\end{array}$ & $\begin{array}{c}0.245 \\
(0.167)\end{array}$ & $\begin{array}{c}2.845^{* * *} \\
(0.722)\end{array}$ & $\begin{array}{c}1.271 * * * \\
(0.375)\end{array}$ \\
\hline Girl & $\begin{array}{c}-0.664^{* *} \\
(0.261)\end{array}$ & $\begin{array}{c}-0.424 * * * \\
(0.115)\end{array}$ & $\begin{array}{c}-8.757 * * * \\
(0.521)\end{array}$ & $\begin{array}{c}-3.610^{* * *} \\
(0.263)\end{array}$ \\
\hline Mean of Y for first-born boy & 1.459 & 0.514 & 10.855 & 3.974 \\
\hline Number of children & 39,386 & 68,234 & 39,386 & 68,234 \\
\hline \multirow[t]{3}{*}{ Number of families } & 19,693 & 34,117 & 19,693 & 34,117 \\
\hline & \multicolumn{4}{|c|}{ Panel C. Denmark: Incarcerated } \\
\hline & \multicolumn{2}{|c|}{ By age 16} & \multicolumn{2}{|c|}{ By age 21} \\
\hline Second-born & $\begin{array}{c}0.454 * * * \\
(0.127)\end{array}$ & $\begin{array}{c}0.075 \\
(0.056)\end{array}$ & $\begin{array}{l}0.862^{*} \\
(0.478)\end{array}$ & $\begin{array}{c}0.515^{* *} \\
(0.216)\end{array}$ \\
\hline Girl & $\begin{array}{c}0.035 \\
(0.088)\end{array}$ & $\begin{array}{l}-0.004 \\
(0.036)\end{array}$ & $\begin{array}{c}-4.125^{* * *} \\
(0.336)\end{array}$ & $\begin{array}{c}-1.106^{* * *} \\
(0.144)\end{array}$ \\
\hline Mean of Y for first-born boy & 0.099 & 0.051 & 4.158 & 1.187 \\
\hline Number of children & 39,386 & 68,234 & 39,386 & 68,234 \\
\hline \multirow[t]{3}{*}{ Number of families } & 19,693 & 34,117 & 19,693 & 34,117 \\
\hline & \multicolumn{4}{|c|}{ Panel D. Florida: Behavioral outcomes in school } \\
\hline & \multicolumn{2}{|c|}{ Suspensions (G1 to G8) } & \multicolumn{2}{|c|}{ Absences (G4 to G8) } \\
\hline Second-born & $\begin{array}{c}2.883 * * * \\
(0.826)\end{array}$ & $\begin{array}{c}1.421 * * * \\
(0.225)\end{array}$ & $\begin{array}{c}0.084 \\
(0.161)\end{array}$ & $\begin{array}{c}0.158^{* * *} \\
(0.040)\end{array}$ \\
\hline Girl & $\begin{array}{c}-7.478^{* * *} \\
(0.696)\end{array}$ & $\begin{array}{c}-3.836^{* * *} \\
(0.177)\end{array}$ & $\begin{array}{l}-0.154 \\
(0.134)\end{array}$ & $\begin{array}{c}-0.117 * * * \\
(0.032)\end{array}$ \\
\hline Mean of $Y$ for first-born boy & 12.439 & 5.096 & 5.349 & 5.558 \\
\hline Number of observations & 40,980 & 308,204 & 23,186 & 176,970 \\
\hline Number of children & 8,760 & 67,276 & 7,506 & 58,930 \\
\hline Number of families & 4,380 & 33,638 & 3,753 & 29,465 \\
\hline
\end{tabular}

Note: Standard errors clustered at mother level. All estimates come from fixed effects regressions controlling for child birth year dummies. 
Table 9: Heterogeneity effects by immigration origin of the parents

\begin{tabular}{|c|c|c|c|c|}
\hline & $(1)$ & $(2)$ & (3) & $(4)$ \\
\hline & Native-born & Immigrant & Native-born & Immigrant \\
\hline & \multicolumn{4}{|c|}{ Panel A. Denmark: Convictions } \\
\hline & \multicolumn{2}{|c|}{ By age 16} & \multicolumn{2}{|c|}{ By age 21} \\
\hline \multirow[t]{2}{*}{ Second-born } & $0.895^{* * *}$ & $3.629 * * *$ & $2.705^{* * *}$ & $6.375^{* * *}$ \\
\hline & $(0.321)$ & $(0.856)$ & $(0.524)$ & $(1.214)$ \\
\hline \multirow[t]{2}{*}{ Girl } & $-2.101 * * *$ & $-6.277 * * *$ & $-11.072 * * *$ & $-16.572 * * *$ \\
\hline & $(0.222)$ & $(0.725)$ & $(0.376)$ & $(1.029)$ \\
\hline Mean of Y for first-born boy & 3.860 & 8.046 & 14.847 & 22.100 \\
\hline Number of children & 102,898 & 18,202 & 102,898 & 18,202 \\
\hline \multirow[t]{3}{*}{ Number of families } & 51,449 & 9,101 & 51,449 & 9,101 \\
\hline & \multicolumn{4}{|c|}{ Panel B. Denmark: Sentenced to prison } \\
\hline & \multicolumn{2}{|c|}{ By age 16} & \multicolumn{2}{|c|}{ By age 21} \\
\hline \multirow[t]{2}{*}{ Second-born } & $0.404 * *$ & $2.475^{* * *}$ & $1.515^{* * *}$ & $4.469 * * *$ \\
\hline & $(0.174)$ & $(0.529)$ & $(0.363)$ & $(0.978)$ \\
\hline \multirow[t]{2}{*}{ Girl } & $-0.391 * * *$ & $-2.101 * * *$ & $-5.136 * * *$ & $-12.332^{* * *}$ \\
\hline & $(0.118)$ & $(0.446)$ & $(0.254)$ & $(0.807)$ \\
\hline Mean of Y for first-born boy & 0.795 & 2.807 & 6.236 & 11.204 \\
\hline Number of children & 102,898 & 18,202 & 102,898 & 18,202 \\
\hline \multirow[t]{3}{*}{ Number of families } & 51,449 & 9,101 & 51,449 & 9,101 \\
\hline & \multicolumn{4}{|c|}{ Panel C. Denmark: Incarcerated } \\
\hline & \multicolumn{2}{|c|}{ By age 16} & \multicolumn{2}{|c|}{ By age 21} \\
\hline \multirow[t]{2}{*}{ Second-born } & $0.129 * * *$ & $0.889 * * *$ & $0.527 * *$ & $2.371 * * *$ \\
\hline & $(0.049)$ & $(0.281)$ & $(0.225)$ & $(0.707)$ \\
\hline \multirow[t]{2}{*}{ Girl } & -0.003 & $-0.500^{* *}$ & $-1.958^{* * *}$ & $-6.284 * * *$ \\
\hline & $(0.035)$ & $(0.233)$ & $(0.151)$ & $(0.577)$ \\
\hline Mean of Y for first-born boy & 0.045 & 0.764 & 2.112 & 5.251 \\
\hline Number of children & 102,898 & 18,202 & 102,898 & 18,202 \\
\hline \multirow[t]{3}{*}{ Number of families } & 51,449 & 9,101 & 51,449 & 9,101 \\
\hline & \multicolumn{4}{|c|}{ Panel D. Florida: Behavioral outcomes in school } \\
\hline & \multicolumn{2}{|c|}{ Suspensions (G1 to G8) } & \multicolumn{2}{|c|}{ Absences (G4 to G8) } \\
\hline \multirow[t]{2}{*}{ Second-born } & $1.737 * * *$ & $1.655^{* * *}$ & $0.117 * *$ & $0.264 * * *$ \\
\hline & $(0.265)$ & $(0.396)$ & $(0.048)$ & $(0.072)$ \\
\hline \multirow[t]{2}{*}{ Girl } & $-4.573^{* * *}$ & $-3.137 * * *$ & $-0.121 * * *$ & $-0.122 * *$ \\
\hline & $(0.204)$ & $(0.341)$ & $(0.038)$ & $(0.062)$ \\
\hline Mean of Y for first-born boy & 6.294 & 4.542 & 3.832 & 2.901 \\
\hline Number of observations & 278,674 & 70,510 & 159,454 & 40,702 \\
\hline Number of children & 60,546 & 15,490 & 52,840 & 13,596 \\
\hline Number of families & 30,273 & 7,745 & 26,420 & 6,798 \\
\hline
\end{tabular}

Note: Standard errors clustered at mother level. All estimates come from fixed effects regressions controlling for child birth year dummies. We define immigrants in Florida based on the fact that mother was born outside of the US while in Denmark if either of the parents were born outside of Denmark. 
Table 10: Heterogeneity effects by race and ethnicity: Florida birth cohorts 1994-2002

\begin{tabular}{lcccc}
\hline & $(1)$ & $(2)$ & $(3)$ & $(4)$ \\
& Suspensions & $(G 1-G 8)$ & \multicolumn{2}{c}{ Absences (G4-G8) } \\
\hline & African & Non-African & African & Non-African \\
& American & American & American & American \\
Second-born & $2.215^{* *}$ & $1.584 * * *$ & -0.014 & $0.172^{* * *}$ \\
& $(0.871)$ & $(0.224)$ & $(0.107)$ & $(0.043)$ \\
Girl & $-8.928^{* * *}$ & $-3.731^{* * *}$ & $-0.272 * * *$ & $-0.103 * * *$ \\
& $(0.786)$ & $(0.174)$ & $(0.094)$ & $(0.035)$ \\
Mean of Y for first-born boy & 12.384 & 5.183 & 3.223 & 3.691 \\
Number of observations & 36,696 & 312,488 & 20,826 & 179,330 \\
Number of children & 8,284 & 67,752 & 7,138 & 59,298 \\
Number of families & 4,142 & 33,876 & 3,569 & 29,649 \\
& & & & \\
& Pispanic & Non-Hispanic & Hispanic & Non-Hispanic \\
\hline Second-born & $1.501 * * *$ & $1.809 * * *$ & $0.247 * * *$ & $0.117 * *$ \\
Girl & $(0.399)$ & $(0.268)$ & $(0.073)$ & $(0.048)$ \\
& $-3.870^{* * *}$ & $-4.389 * * *$ & $-0.209 * * *$ & $-0.094^{* *}$ \\
Mean of Y for first-born boy & $(0.350)$ & $(0.204)$ & $(0.061)$ & $(0.038)$ \\
Number of observations & 5.264 & 6.142 & 3.368 & 3.725 \\
Number of children & 78,578 & 270,606 & 44,998 & 155,158 \\
Number of families & 17,296 & 58,740 & 15,116 & 51,320 \\
\hline
\end{tabular}

Note: Standard errors clustered at mother level. All estimates come from fixed effects regressions controlling for child birth year dummies. We define race and ethnicity based on maternal information at birth. 
Figure 1: Birth order effects on criminal activity in early adulthood: Estimates for second-borns by age in Denmark

A. Convicted

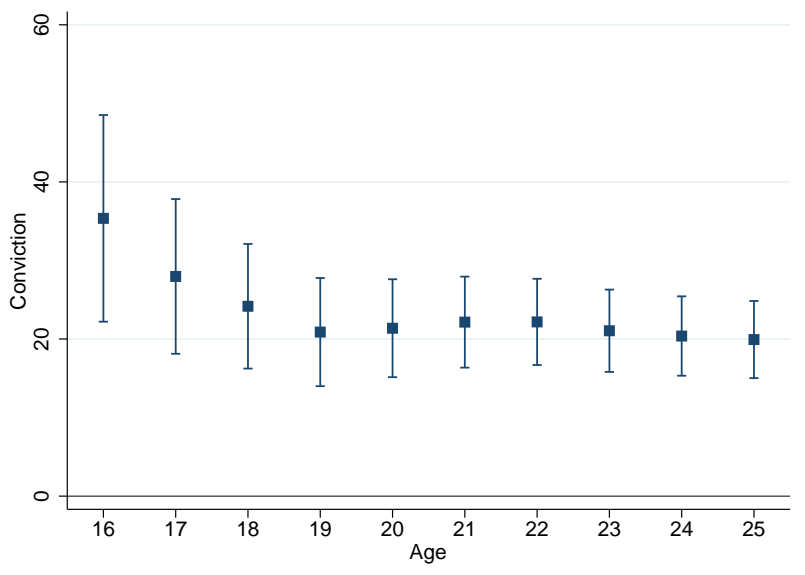

B. Sentenced to prison

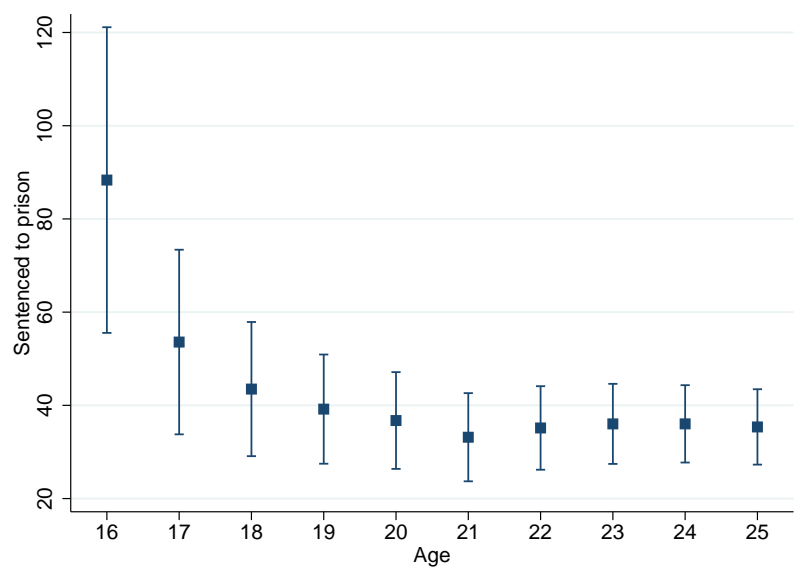

\section{Incarcerated}

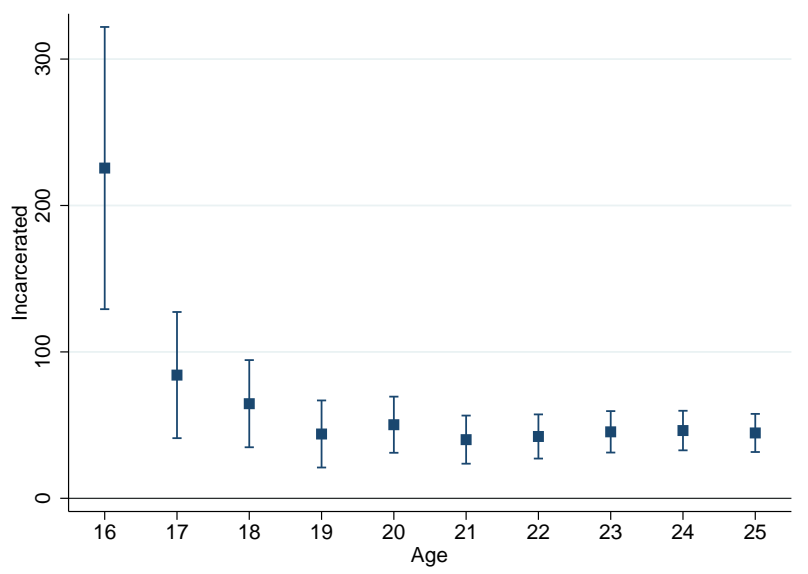

Note: All estimates come from fixed effects regressions controlling for child birth year dummies and are scaled by means of dependent variable for first-born boy in a given group. Dependent variables are delinquency measures by given age. Standard errors clustered at mother level with reported $95 \%$ confidence intervals. Estimates based on boy-boy and girl-boy sample. 
Figure 2: Birth order effects on delinquency in childhood: Estimates by grade in Florida
A. Suspensions
B. Absence rate
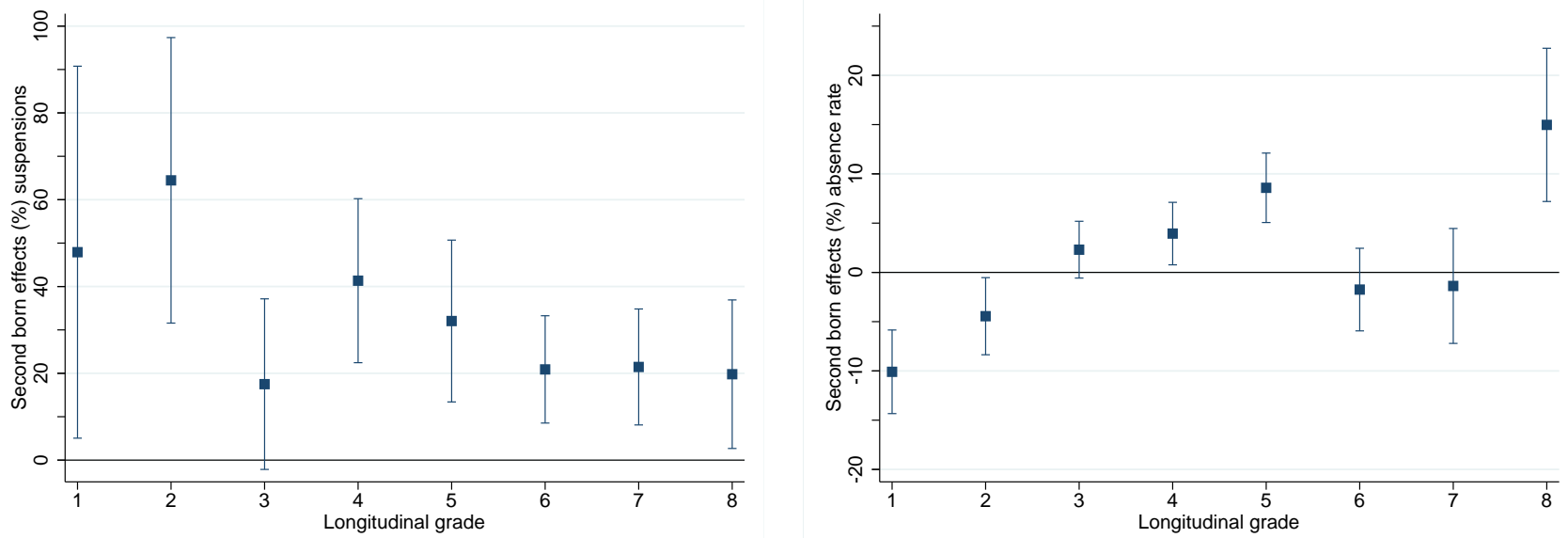

Note: Estimates based on boy-boy and girl-boy sample. Dependent variables are delinquency measures in a given grade. For further details see notes in Figure 1.

Figure 3: Birth order effects on cognitive development in childhood: Estimates by grade in Florida

A. Mathematics

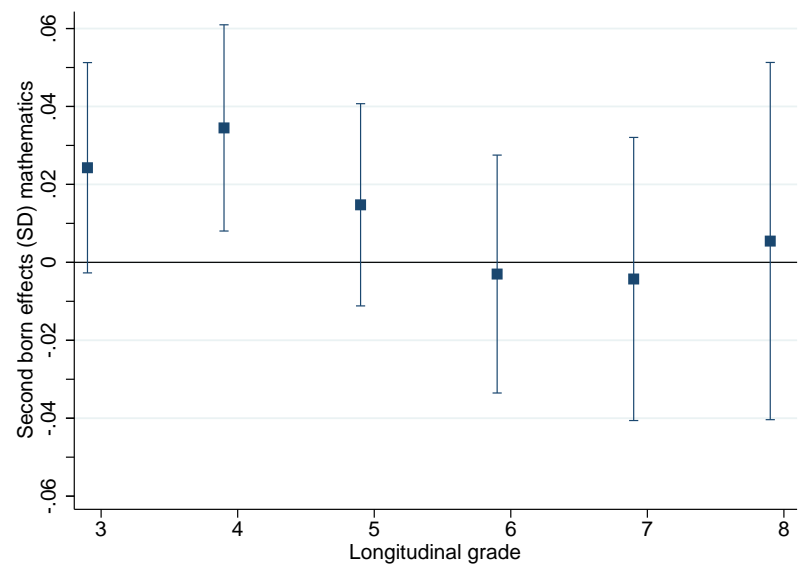

B. Reading

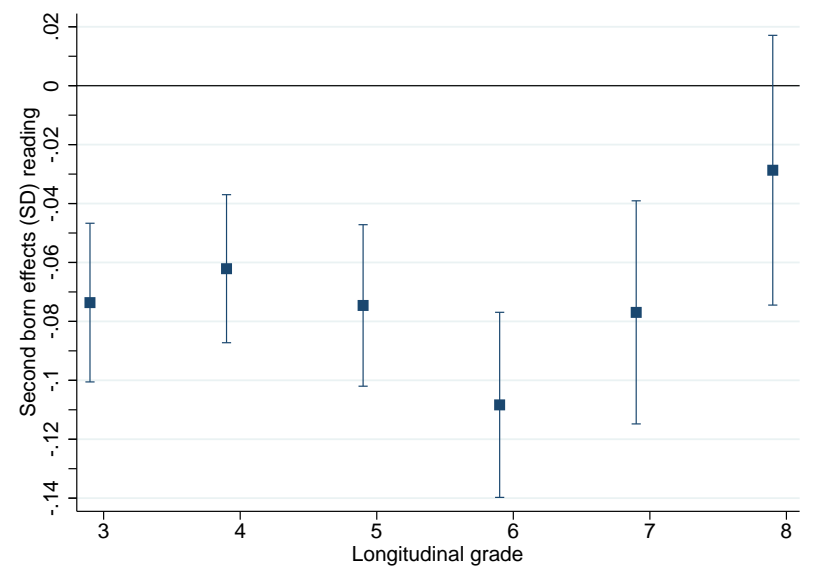

Note: Estimates based on boy-boy and girl-boy sample. Dependent variables are mathematics or reading test score in a given grade. For further details see notes in Figure 1. 
Figure 4: Maternal labor market activity after birth: Estimates for Denmark
A. Any employment
B. Full time employment
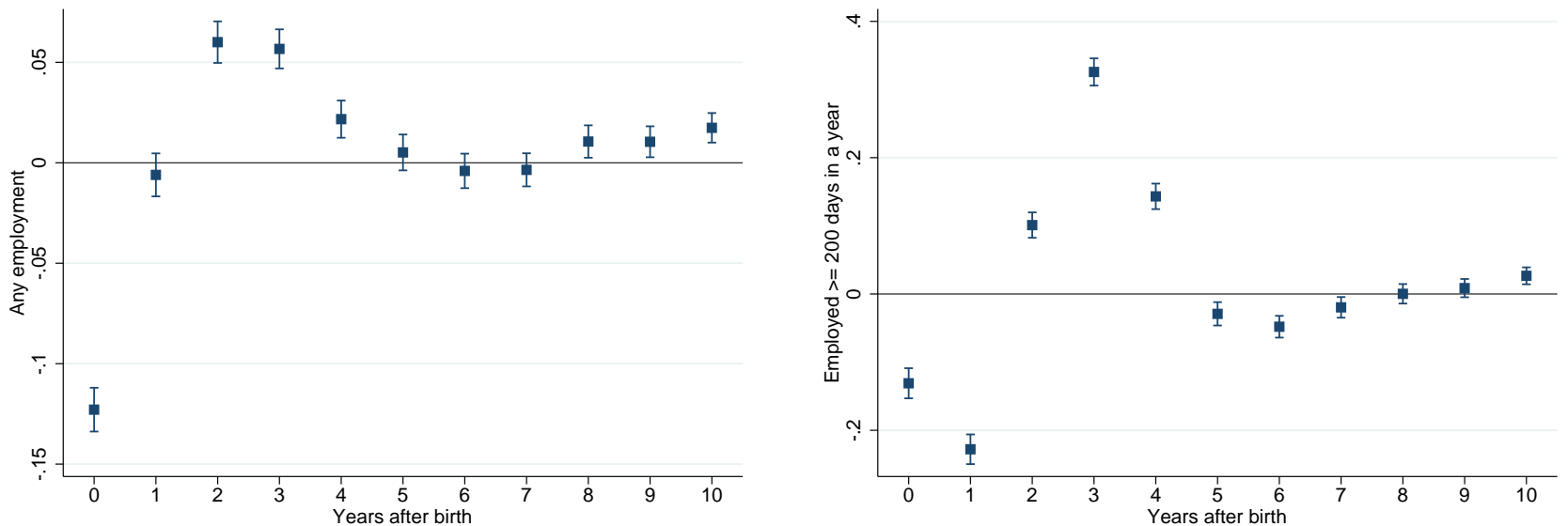

Note: Estimates based on boy-boy and girl-boy sample. Dependent variables are maternal employment measures in a given year after child birth i.e. being employed 1st year after birth, 2nd year after birth etc. For further details see notes in Figure 1.

Figure 5: Birth order effects on attended school quality: Estimates by grade in Florida
A. Attended A rated school
B. School quality (0 to 4 scale)
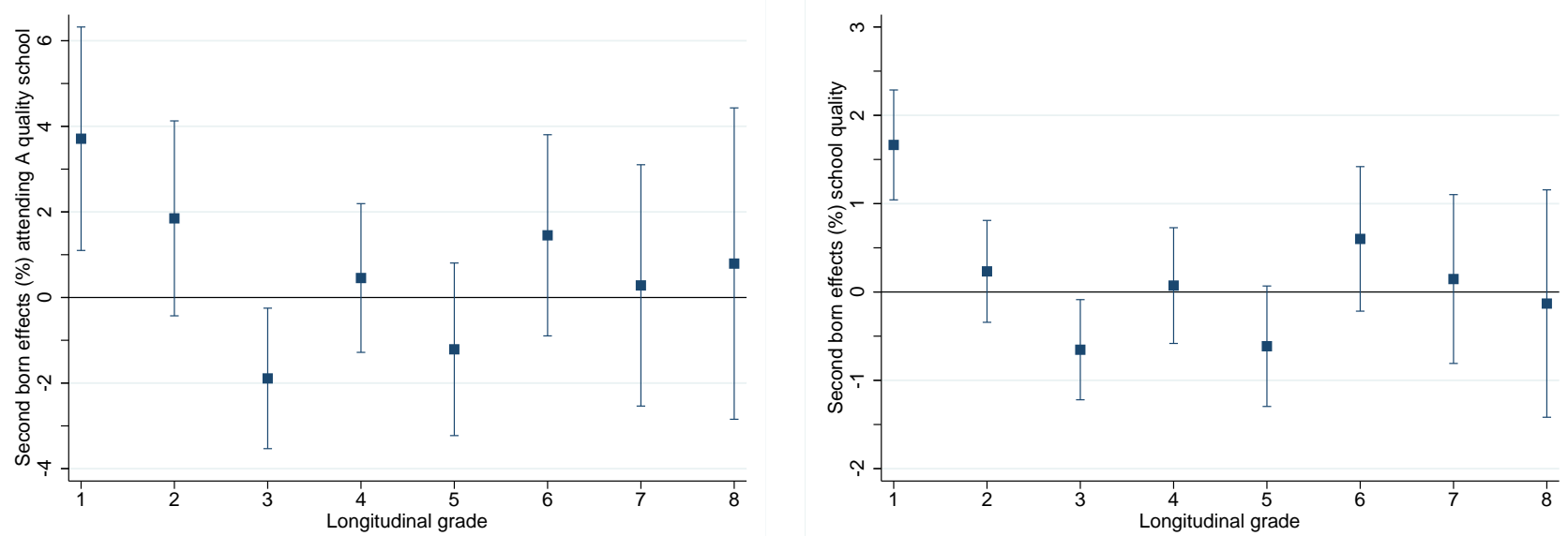

Note: Estimates based on boy-boy and girl-boy sample. Dependent variables are school quality measures in a given grade. For further details see notes in Figure 1. 


\section{Appendix Tables}

Table A1: Short-run non-cognitive outcomes: Denmark birth cohorts 1999-2000

\begin{tabular}{|c|c|c|c|c|}
\hline & (1) & $(2)$ & (3) & (4) \\
\hline & Close to average & Slightly raised & High & Very high \\
\hline & \multicolumn{4}{|c|}{ Panel A: Emotional problems score } \\
\hline \multirow[t]{2}{*}{ Second-born } & -0.002 & 0.008 & -0.013 & 0.006 \\
\hline & $(0.020)$ & $(0.014)$ & $(0.010)$ & $(0.011)$ \\
\hline \multirow[t]{2}{*}{ Girl } & $-0.114 * * *$ & $0.031 * *$ & 0.011 & $0.071 * * *$ \\
\hline & $(0.019)$ & $(0.014)$ & $(0.011)$ & $(0.012)$ \\
\hline \multirow[t]{2}{*}{ Mean of Y for first-born boy } & 0.878 & 0.059 & 0.041 & 0.022 \\
\hline & \multicolumn{4}{|c|}{ Panel B: Conduct problems score } \\
\hline \multirow[t]{2}{*}{ Second-born } & -0.013 & -0.002 & -0.000 & 0.016 \\
\hline & $(0.021)$ & $(0.016)$ & $(0.012)$ & $(0.010)$ \\
\hline \multirow[t]{2}{*}{ Girl } & $0.051 * * *$ & -0.016 & $-0.029 * * *$ & -0.006 \\
\hline & $(0.017)$ & $(0.013)$ & $(0.010)$ & $(0.008)$ \\
\hline \multirow[t]{2}{*}{ Mean of Y for first-born boy } & 0.847 & 0.079 & 0.051 & 0.023 \\
\hline & \multicolumn{4}{|c|}{ Panel C: Hyperactivity score } \\
\hline \multirow[t]{2}{*}{ Second-born } & $-0.049 * *$ & -0.005 & $0.029 * *$ & 0.024 \\
\hline & $(0.023)$ & $(0.017)$ & $(0.012)$ & $(0.015)$ \\
\hline \multirow[t]{2}{*}{ Girl } & $0.041 * *$ & -0.016 & -0.007 & -0.019 \\
\hline & $(0.019)$ & $(0.013)$ & $(0.010)$ & $(0.011)$ \\
\hline \multirow[t]{2}{*}{ Mean of Y for first-born boy } & 0.820 & 0.080 & 0.040 & 0.061 \\
\hline & \multicolumn{4}{|c|}{ Panel D: Peer problems score } \\
\hline \multirow[t]{2}{*}{ Second-born } & -0.013 & -0.024 & 0.023 & 0.013 \\
\hline & $(0.029)$ & $(0.022)$ & $(0.019)$ & $(0.018)$ \\
\hline \multirow[t]{2}{*}{ Girl } & $0.079 * * *$ & $-0.052 * * *$ & $-0.024 *$ & -0.003 \\
\hline & $(0.024)$ & $(0.018)$ & $(0.014)$ & $(0.015)$ \\
\hline Mean of Y for first-born boy & 0.638 & 0.170 & 0.097 & 0.095 \\
\hline Number of children & \multicolumn{4}{|c|}{3,370} \\
\hline
\end{tabular}

Note: Standard errors clustered at mother level. All outcome variables are binary indicators. OLS regressions in columns (1)-(4) include the following controls: child birth year dummies, mother's age at first birth, mother's age, father's age, municipality dummies, maternal and paternal education, maternal and paternal employment, family income, immigrant dummy, number of children in family. The questionnaire was answered by 6th grade students from birth cohorts 1998-2000. These are sub-scores for the results reported in panel A of Table 4. 
Table A2: Daycare by age of the child: Denmark birth cohorts 1993-2000

\begin{tabular}{lccc}
\hline & $(1)$ & $(2)$ & $(3)$ \\
& At age 1 & At age 2 & At age 3 \\
\hline Second-born & $-0.172^{* * *}$ & $0.034^{* * *}$ & $0.108^{* * *}$ \\
Girl & $(0.007)$ & $(0.006)$ & $(0.006)$ \\
& -0.002 & -0.007 & $-0.011 * * *$ \\
Mean of Y for first-born boy & $(0.005)$ & $(0.004)$ & $(0.004)$ \\
Number of children/families & 0.160 & 0.667 & 0.764 \\
\hline
\end{tabular}

Note: Standard errors clustered at mother level. All estimates come from fixed effects regressions controlling for child birth year dummies. 


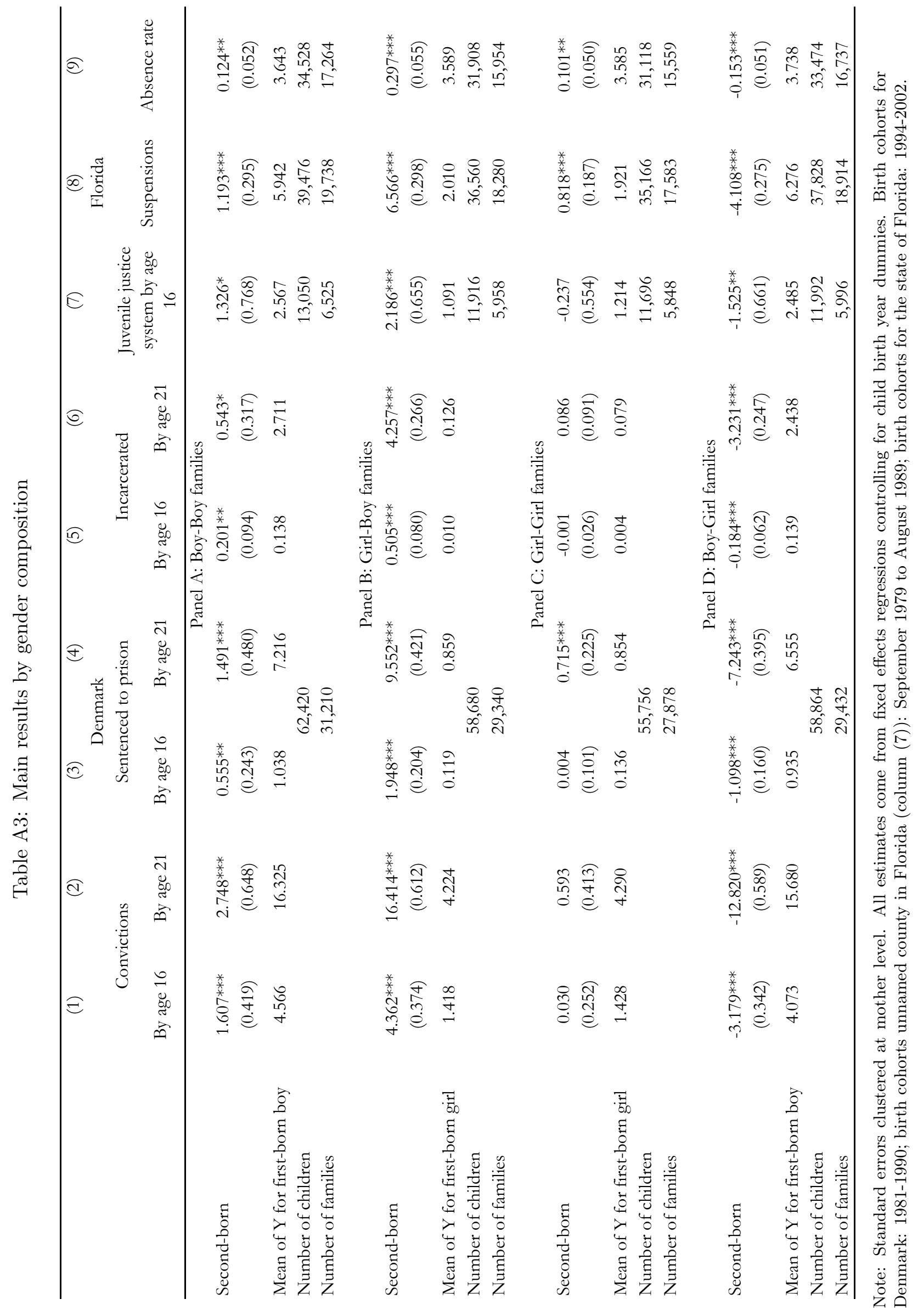


Table A4: Heterogeneity effects by maternal employment: Denmark birth cohorts 1981-1990

\begin{tabular}{|c|c|c|c|c|}
\hline & $\begin{array}{c}\text { (1) } \\
\text { Non-employed }\end{array}$ & $\begin{array}{c}(2) \\
\text { Employed }\end{array}$ & $\begin{array}{c}\text { (3) } \\
\text { Non-employed }\end{array}$ & $\begin{array}{c}(4) \\
\text { Employed }\end{array}$ \\
\hline & \multicolumn{4}{|c|}{ Panel A. Convictions } \\
\hline & \multicolumn{2}{|c|}{ By age 16} & \multicolumn{2}{|c|}{ By age 21} \\
\hline Second-born & $\begin{array}{c}2.849 * * \\
(1.158)\end{array}$ & $\begin{array}{c}0.716^{* *} \\
(0.365)\end{array}$ & $\begin{array}{l}4.018^{* *} \\
(1.690)\end{array}$ & $\begin{array}{c}3.023 * * * \\
(0.603)\end{array}$ \\
\hline Girl & $\begin{array}{c}-3.018^{* * *} \\
(0.826)\end{array}$ & $\begin{array}{c}-2.161^{* * *} \\
(0.248)\end{array}$ & $\begin{array}{c}-14.566^{* * *} \\
(1.259)\end{array}$ & $\begin{array}{c}-11.088^{* * *} \\
(0.424)\end{array}$ \\
\hline \multirow[t]{3}{*}{ Mean of Y for first-born boy } & 5.998 & 3.805 & 21.923 & 14.451 \\
\hline & \multicolumn{4}{|c|}{ Panel B. Sentenced to prison } \\
\hline & \multicolumn{2}{|c|}{ By age 16} & \multicolumn{2}{|c|}{ By age 21} \\
\hline Second-born & $\begin{array}{c}1.910^{* * *} \\
(0.630)\end{array}$ & $\begin{array}{c}0.201 \\
(0.203)\end{array}$ & $\begin{array}{c}3.522^{* * *} \\
(1.272)\end{array}$ & $\begin{array}{c}1.574 * * * \\
(0.414)\end{array}$ \\
\hline Girl & $\begin{array}{l}-0.457 \\
(0.469)\end{array}$ & $\begin{array}{c}-0.589 * * * \\
(0.135)\end{array}$ & $\begin{array}{c}-7.330 * * * \\
(0.930)\end{array}$ & $\begin{array}{c}-5.211 * * * \\
(0.284)\end{array}$ \\
\hline \multirow[t]{3}{*}{ Mean of Y for first-born boy } & 1.413 & 0.847 & 10.514 & 5.999 \\
\hline & \multicolumn{4}{|c|}{ Panel C. Incarcerated } \\
\hline & \multicolumn{2}{|c|}{ By age 16} & \multicolumn{2}{|c|}{ By age 21} \\
\hline Second-born & $\begin{array}{c}0.646^{* *} \\
(0.278)\end{array}$ & $\begin{array}{l}0.097^{*} \\
(0.054)\end{array}$ & $\begin{array}{l}1.907 * * \\
(0.860)\end{array}$ & $\begin{array}{c}0.544^{* *} \\
(0.253)\end{array}$ \\
\hline Girl & $\begin{array}{c}0.088 \\
(0.172)\end{array}$ & $\begin{array}{l}-0.038 \\
(0.041)\end{array}$ & $\begin{array}{c}-2.878^{* * *} \\
(0.610)\end{array}$ & $\begin{array}{c}-1.960 * * * \\
(0.166)\end{array}$ \\
\hline Mean of Y for first-born boy & 0.138 & 0.048 & 3.895 & 2.040 \\
\hline Number of children & 11,426 & 80,286 & 11,426 & 80,286 \\
\hline Number of families & 5,713 & 40,143 & 5,713 & 40,143 \\
\hline
\end{tabular}

Note: Maternal employment is defined as a mother working full or part time one year after birth. Standard errors clustered at mother level. All estimates come from fixed effects regressions controlling for child birth year dummies. 


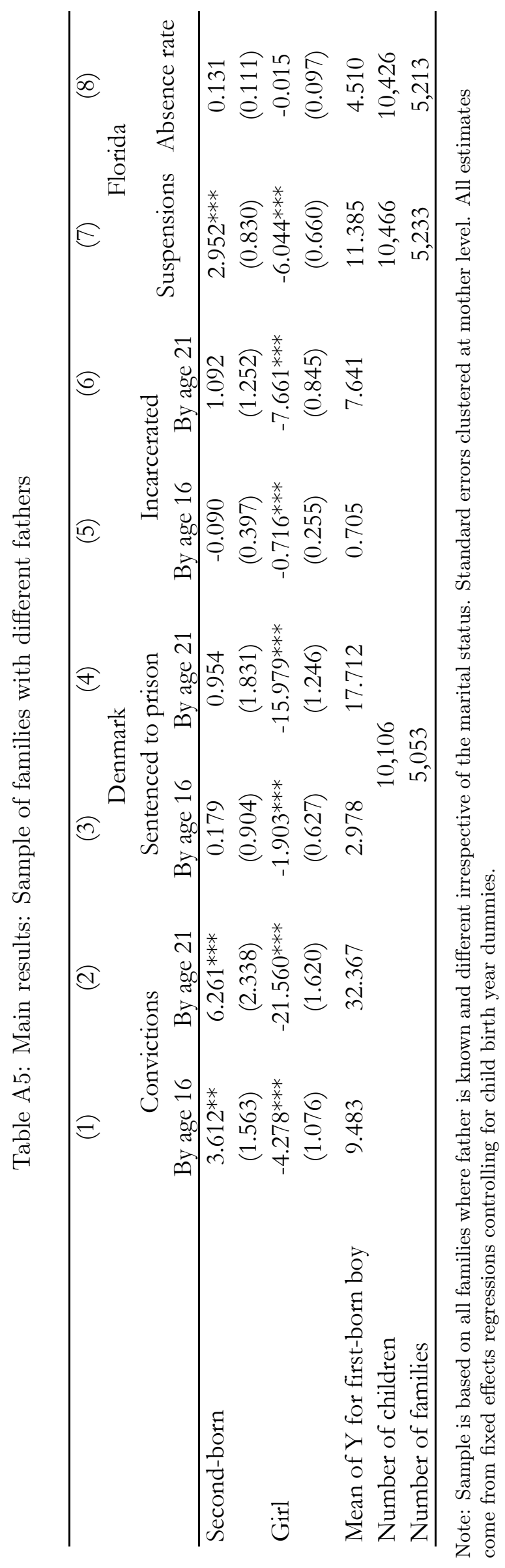




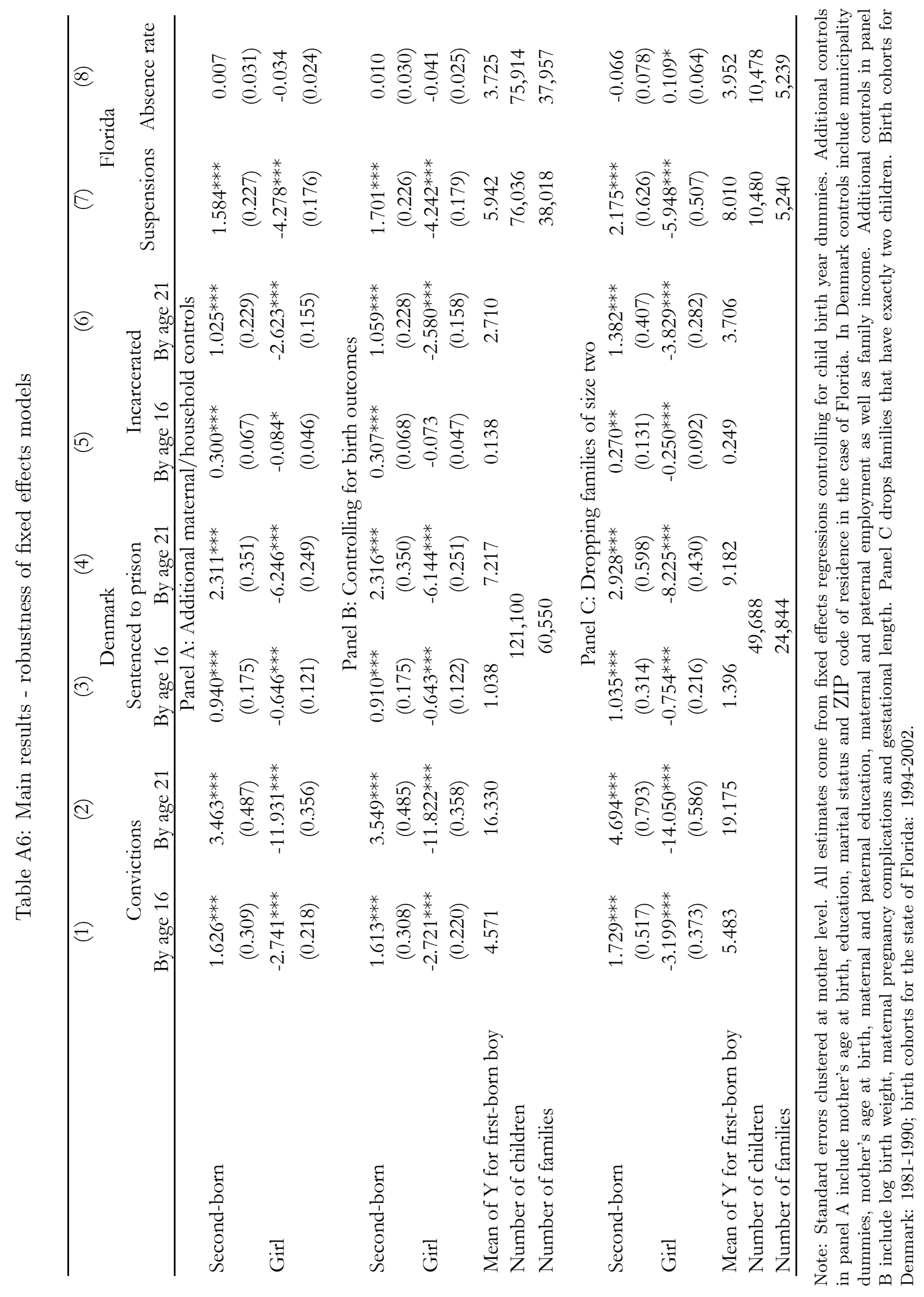




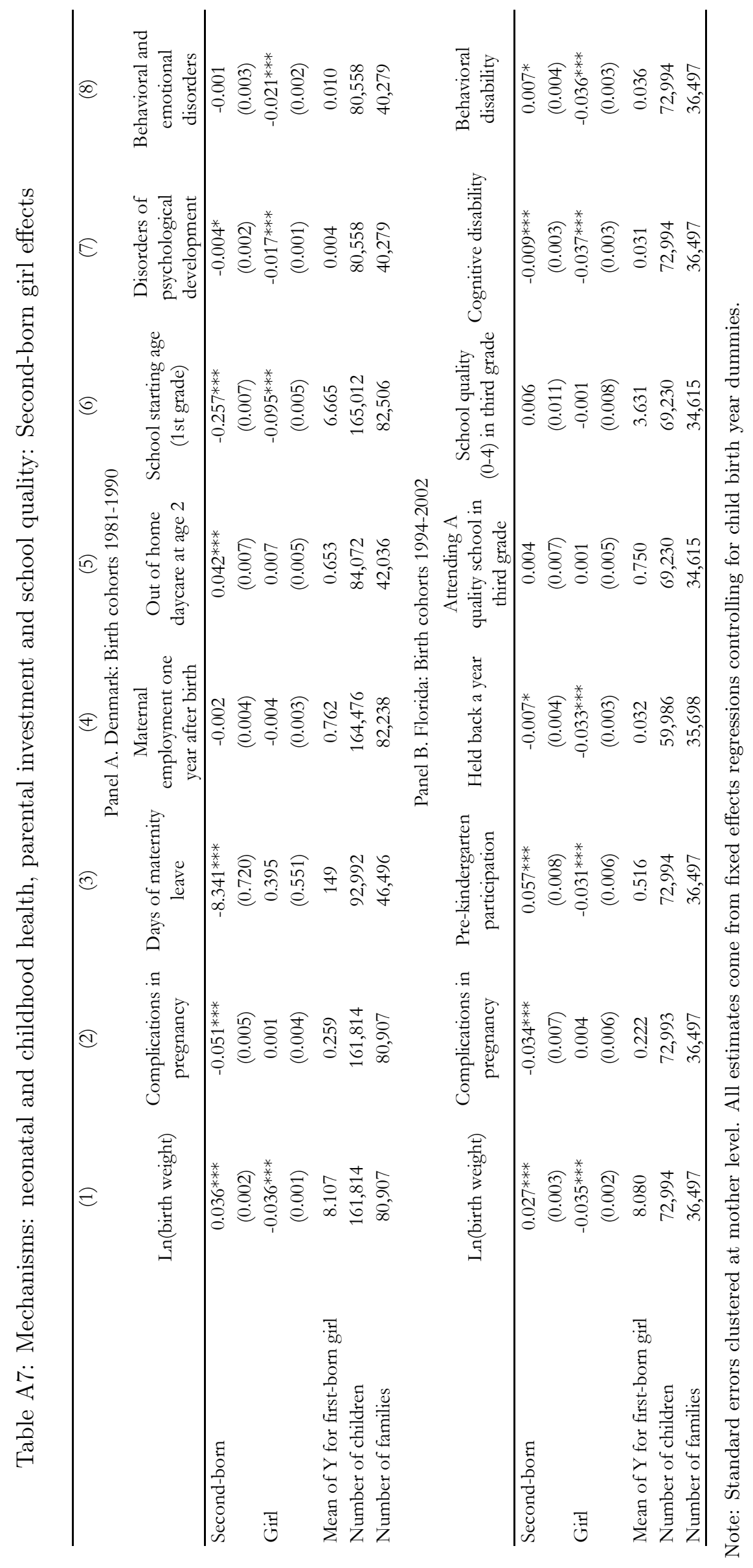




\section{Appendix Figures}

Figure A1: Birth order effects on criminal activity in early adulthood: Estimates for second-borns by age in Denmark

\section{A. Convicted}

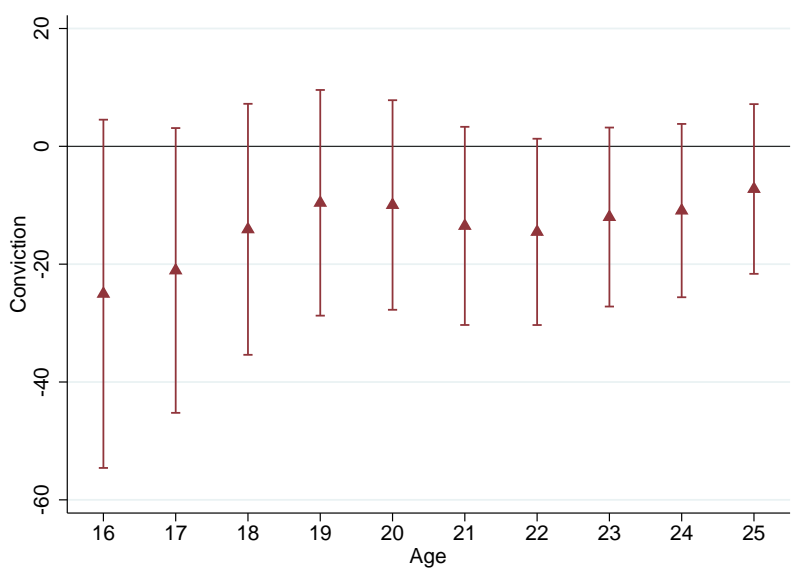

B. Sentenced to prison

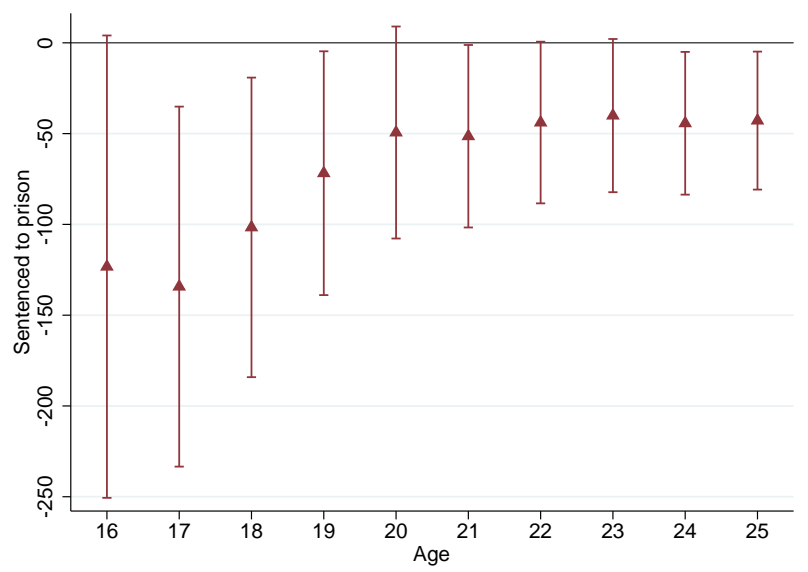

C. Incarcerated

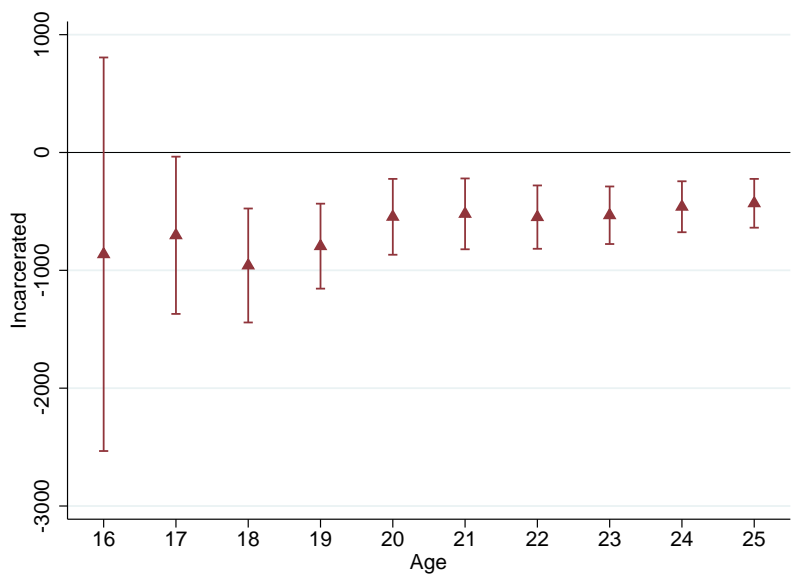

Note: All estimates come from fixed effects regressions controlling for child birth year dummies and are scaled by means of dependent variable for first-born girl in a given group. Dependent variables are delinquency measures by given age. Standard errors clustered at mother level with reported $95 \%$ confidence intervals. Estimates based on girl-girl and boy-girl sample. 
Figure A2: Birth order effects on delinquency in childhood: Estimates by grade in Florida

A. Suspensions

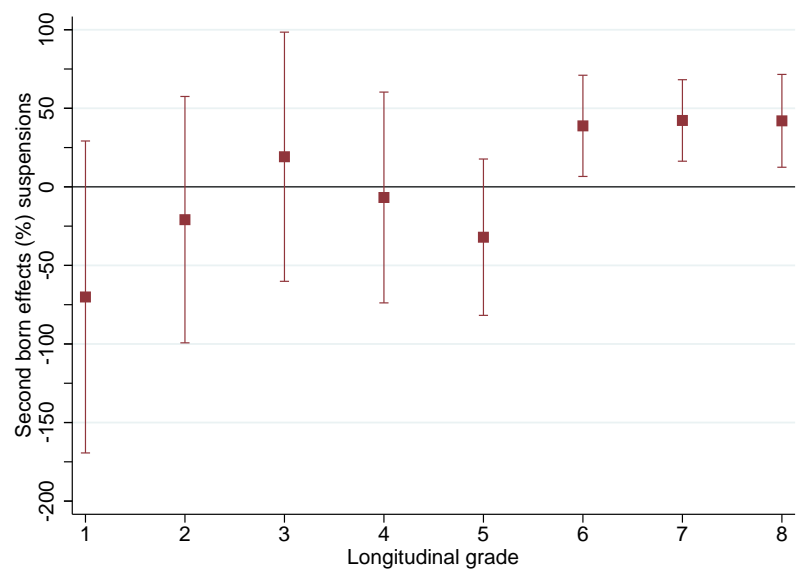

B. Absence rate

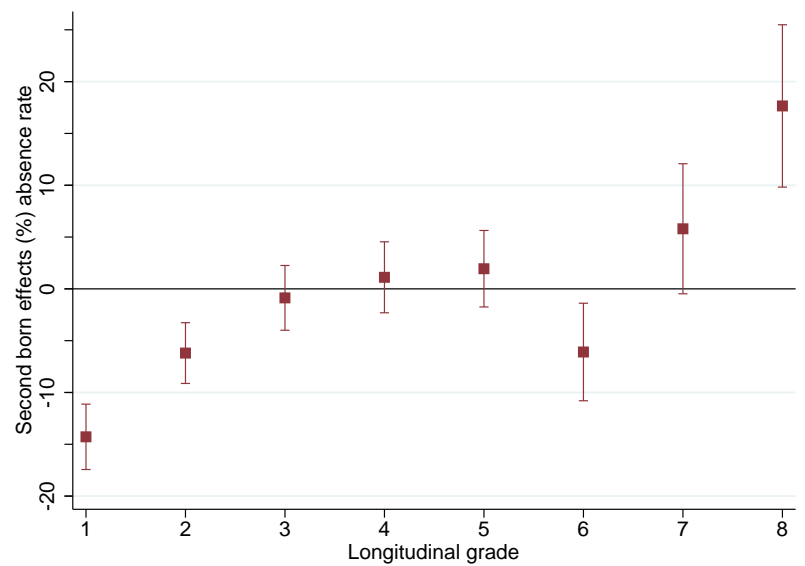

Note: Estimates based on girl-girl and boy-girl sample. Dependent variables are delinquency measures in a given grade. For further details see notes in Figure A1.

Figure A3: Birth order effects on cognitive development in childhood: Estimates by grade in Florida

A. Mathematics

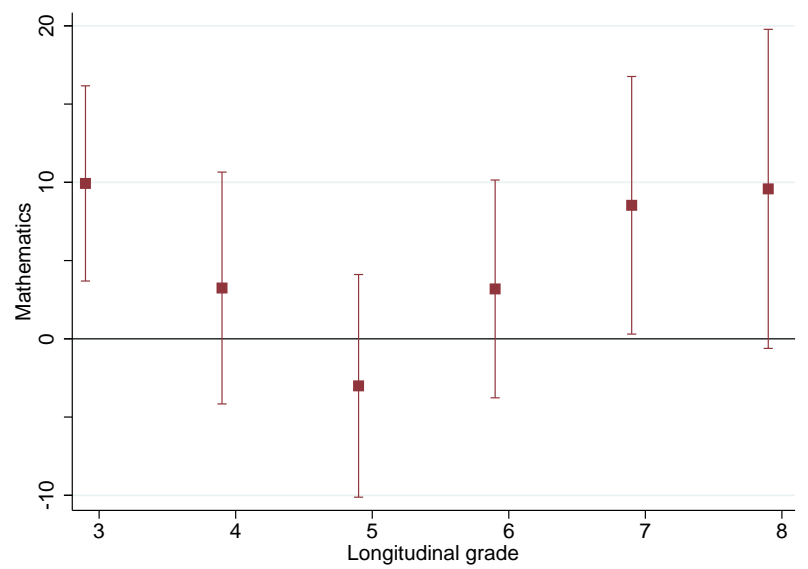

B. Reading

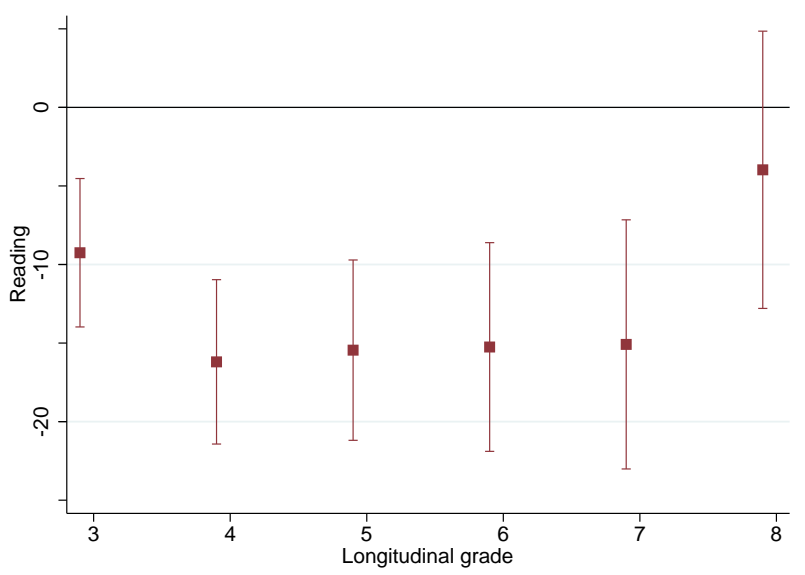

Note: Estimates based on girl-girl and boy-girl sample. Dependent variables are mathematics or reading test score in a given grade. For further details see notes in Figure A1. 
Figure A4: Maternal labor market activity after birth: Estimates for Denmark

A. Any employment

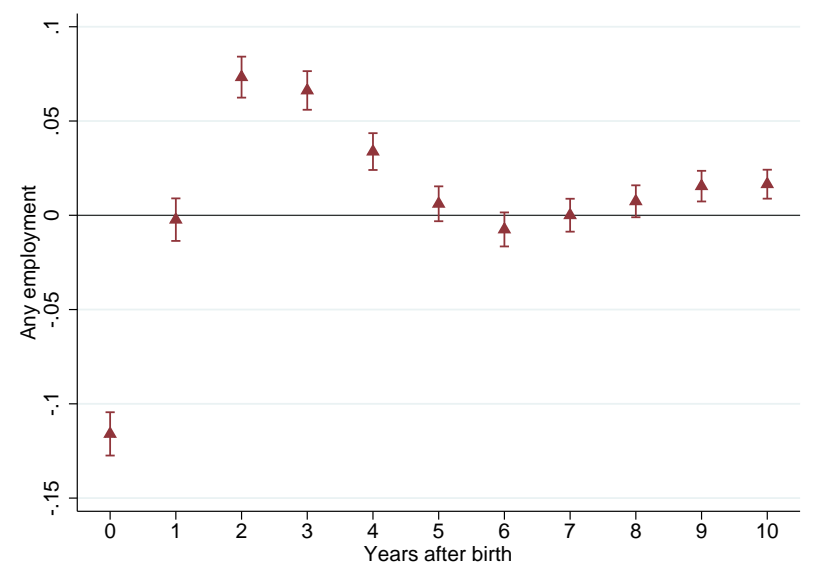

B. Full time employment

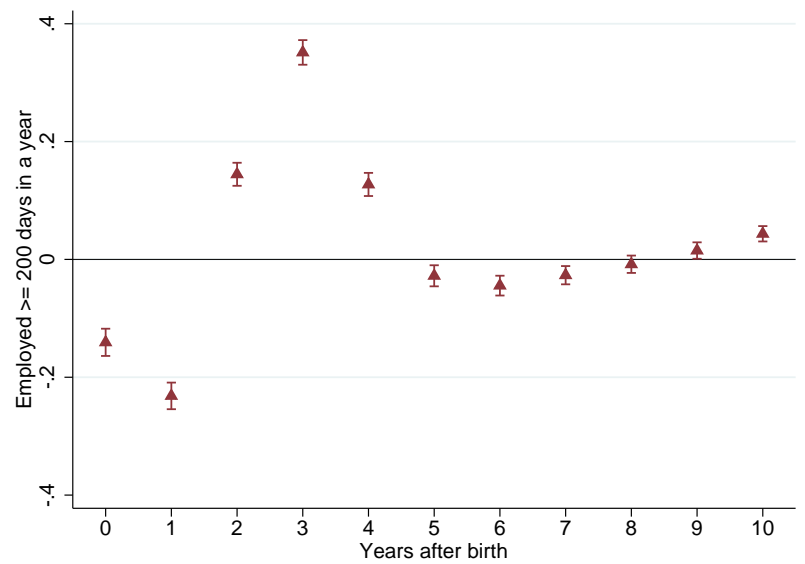

Note: Estimates based on girl-girl and boy-girl sample. Dependent variables are maternal employment measures in a given year after child birth i.e. being employed 1st year after birth, 2nd year after birth etc. For further details see notes in Figure A1.

Figure A5: Birth order effects on attended school quality: Estimates for second-borns by grade in Florida

A. Attended A rated school

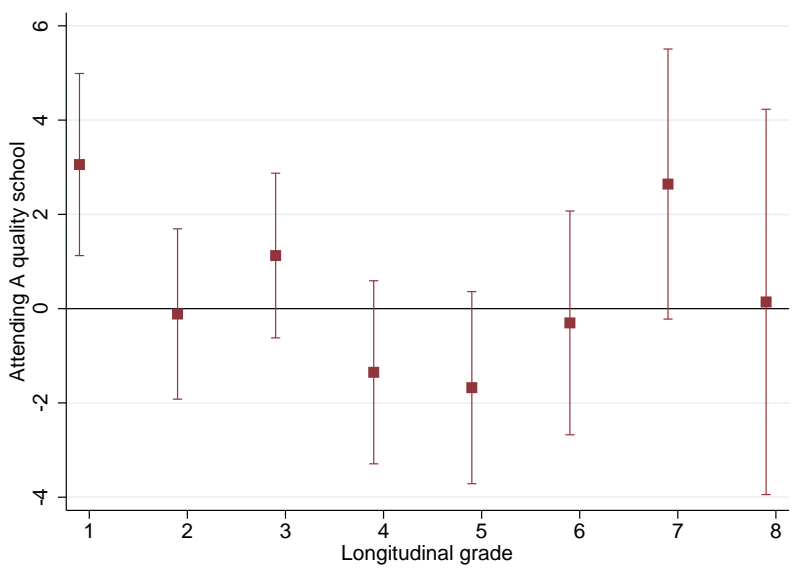

B. School quality (0 to 4 scale)

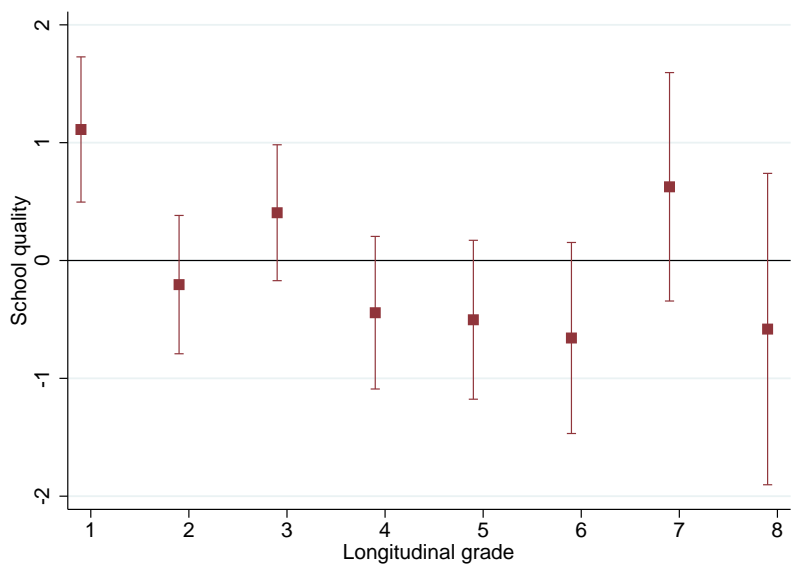

Note: Estimates based on girl-girl and boy-girl sample. Dependent variables are school quality measures in a given grade. For further details see notes in Figure 1. 